AUTARQUIA ASSOCIADA À UNIVERSIDADE DE SÃO PAULO

RESSONÂNCIA PARAMAGNÉTICA ELETRÔNICA E ESPECTROSCOPIA DE INFRAVERMELHO APLICADA NO ESTUDO DE AMIDOS IRRADIADOS

GILBERTO DIAS DA SILVA

Dissertação apresentada como parte dos requisitos para obtenção do Grau de Mestre em Ciências na Área de Tecnologia Nuclear - Aplicações

Orientadora:

Profa. Dra. Nélida Lucia del Mastro 
INSTITUTO DE PESQUISAS ENERGÉTICAS E NUCLEARES

Autarquia associada à Universidade de São Paulo

\title{
RESSONÂNCIA PARAMAGNÉTICA ELETRÔNICA E ESPECTROSCOPIA DE INFRAVERMELHO APLICADA NO ESTUDO DE AMIDOS IRRADIADOS
}

\author{
GILBERTO DIAS DA SILVA
}

Dissertação apresentada como parte dos requisitos para obtenção do Grau de Mestre em Ciências na Área de Tecnologia Nuclear - Aplicações

Orientadora:

Profa. Dra. Nélida Lúcia Del Mastro:

Versão Corrigida

Versão Original disponível no IPEN

São Paulo 


\section{Agradecimentos}

Agradeço :

A Doutora Nélida, pela paciência, pela orientação, pelas sugestões, pelo incentivo e confiança.

Ao Doutor Orlando Rodrigues, pela paciência, pela ajuda nas teorias, pela colaboração nas medições no EPR no Laboratório do Grupo de Metrologia das Radiações (GMR), no IPEN.

A Doutora Áurea Beatriz Cerqueira Geraldo, pelas dicas e sugestões, pela participação na banca do seminário de área, pela ajuda na manipulação do programa Origin. Pela ajuda nas medições do equipamento de infravermelho no CTR -IPEN.

Ao Doutor Silas pela ajuda nas medições no EPR no GRM. Pelas dicas e incentivos.

Ao Centro de Tecnologia das Radiações ( CTR) na utilização dos equipamentos dos Laboratórios de Alimentos, pela utilização do Equipamento de Infravermelho.

A minha mãe, Marinete, pelo apoio e incentivo e pela educação de vida.

Ao Grupo de Metrologia das Radiações (GMR) pela utilização do equipamento de Espectroscopia Paramagnética Eletrônica ( EPR ou RSE).

A minha namorada Rosangela pela paciência nos momentos complicados e pelo incentivo a finalização da dissertação

Aos meus alunos da Escola Estadual João Batista de Brito, pelo incentivo e paciência.

Ao meu amigo Carlos pela ajuda nas traduções de textos acadêmicos.

Ao $\mathrm{CNPq}$, pela bolsa de mestrado 


\section{RESSONÂNCIA PARAMAGNÉTICA ELETRÔNICA E ESPECTROSCOPIA DE INFRAVERMELHO APLICADA NO ESTUDO DE AMIDOS IRRADIADOS Gilberto Dias Da Silva}

\section{RESUMO}

O amido é o mais abundante dos polissacarídeos de armazenamento de energia de plantas, usualmente depositado na forma de grânulos no citoplasma das células. Também é a principal fonte de energia para o homem, compondo 80 $90 \%$ dos polissacarídeos da dieta humana, e é o principal responsável pelas propriedades tecnológicas que caracterizam grande parte dos produtos processados. O presente trabalho teve como objetivo a aplicação da ressonância paramagnética eletrônica (RPE) e espectroscopia de Infravermelho por transformada de Fourier (FTIR) ao estudo de amidos irradiados. Amostras em pó de dois amidos naturais, batata (bulbo) e milho (cereal) e farinha de mandioca fermentada ou polvilho azedo (raiz) foram submetidos à ação da radiação ionizante de fonte de ${ }^{60} \mathrm{Co}$ Gammacell 220 com doses de 10, 20 e 30 kGy, taxa de dose de $1 \mathrm{kGy} \mathrm{h}^{-1}$. Foram registrados e comparados os espectros de RPE dos três tipos de amidos irradiados e não irradiados. Os amidos apresentaram espectros de RPE semelhantes variando apenas na intensidade do sinal de radicais livres que acompanhou o incremento da dose. Foram estabelecidas as curvas de decaimento para cada um dos amidos ensaiados. No caso de amido de batata o decaimento do sinal apresentou excepcionalmente um comportamento linear quando a dose utilizada foi de 20 kGy. Foi obtido de maneira experimental o valor do fator $\mathrm{g}$, que variou de 2,06062 a 1,94661, sendo o valor teórico $g=2,0023$. Foram também estabelecidas as modificações radioinduzidas na estrutura molecular das amostras através da análise dos espectros de absorção no infravermelho por FTIR.

Palavras-chave: Amido, Radiação gama, EPR , FTIR 


\title{
ELECTRONIC PARAMAGNETIC RESONANCE AND INFRARED SPECTROSCOPY APPLIED IN THE STUDY OF IRRADIATED STARCHES
}

\section{Gilberto Dias Da Silva}

\begin{abstract}
Starch is the most abundant plant energy storage polysaccharide, usually deposited in the form of granules in the cytoplasm of cells. It is also the main source of energy for man, making up $80-90 \%$ of polysaccharides in the human diet, and is mainly responsible for the technological properties that characterize most processed products. The present work aimed to the application of electronic paramagnetic resonance and Fourier Transform Infrared Spectroscopy to the study of irradiated starches. Powdered samples of two natural starches, potato (bulb) and corn (cereal) and fermented cassava flour or sour cassava (root) were subjected to the action of ionizing radiation from a ${ }^{60} \mathrm{Co}$ Gammacell 220 at doses of 10,20 and $30 \mathrm{kGy}$, dose rate of $1 \mathrm{kGy} \mathrm{h}^{-1}$.The electronic paramagnetic resonance spectra of the three types of irradiated and non-irradiated starches were recorded and compared. The starches showed similar electronic paramagnetic resonance spectra varying only in the intensity of the free radical signal that accompanied the dose increase. The decay curves were established for each of the tested starches. In the case of potato starch, signal decay showed an exceptionally linear behavior when the dose used was $20 \mathrm{kGy}$. The value of factor $g$ was obtained experimentally, ranging from 2.06062 to 1.94661 , with the theoretical value $g=2.0023$. The radioinduced modifications in the molecular structure of the samples were also established by the analysis of the infrared absorption spectra by Fourier Transform Infrared Spectroscopy.
\end{abstract}

Keywords : Starch, Gamma radiation, EPR, FITR 


\section{SUMÁRIO}

\section{Página}

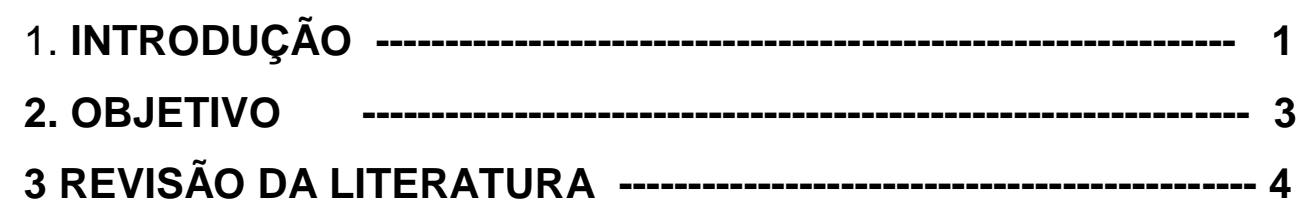

3.1 Amido -

3.2 Ressonância Paramagnética Eletrônica (RPE ou ESR) --------- 9

3.2.1 RPE Interação Hiperfina ----_---11

3.2.2 Efeito Zeeman -----o-11

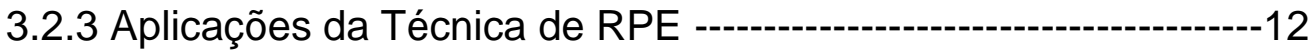

3.2.4 Parâmetros Espectroscópicos ---.-- 13

3.3 Espectroscopia no Infravermelho com Transformada ( FTIR)- 14

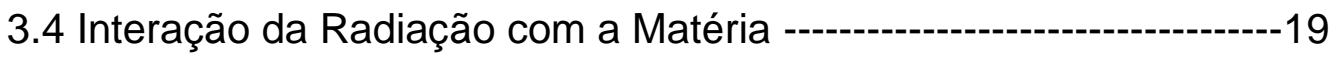

3.4.1 Efeitos da Radiação lonizantes em Produtos Alimentícios -------22

3.4.1.1 Efeito da Irradiação em Amidos -------------------------- 24

4 MATERIAL E MÉTODOS --_- 27

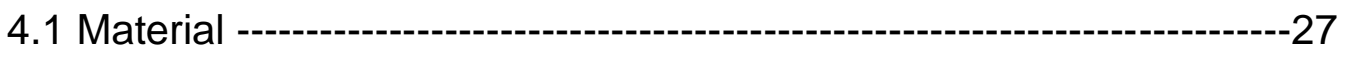

4.2 Métodos ---

4.2.1 Irradiações -----------------------------------------27

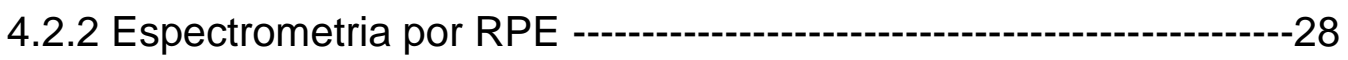

4.2.3 Espectroscopia no Infravermelho (FTIR) -----------------------30

5 RESULTADOS E DISCUSSÃO - -

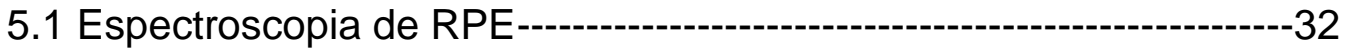

5.2 Decaimento do sinal em Amidos Irradiados ---------------------39

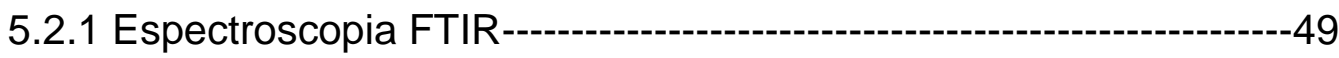

6 CONCLUSÃO -

REFERÊNCIAS BIBLIOGRÁFICAS --- 56 


\section{LISTAS DE TABELAS}

\section{Página}

TABELA 1 - Teores de amilose e amilopectina de algumas espécies vegetais - 6

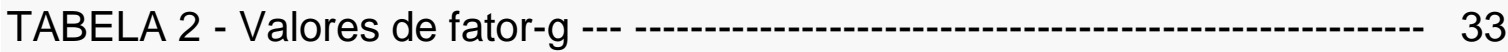

TABELA 3 - Parâmetros da curva de decaimento de sinal de RPE de amido de milho 46

TABELA 4-Parâmetros da curva de decaimento de sinal de RPE de amido de batata47

TABELA 5 - Parâmetros da curva de decaimento de sinal de RPE de polvilho azedo 


\section{LISTA DE FIGURAS}

\section{Página}

FIGURA 1 - Estrutura da amilose (A) e amilopectina (B) 7

FIGURA 2 - Mínimo e Máximo de energia de orientações respeito ao campo magnético $\mathrm{B}_{0}$

FIGURA 3 - Indução das energias do estado de rotação como função do campo magnético $\mathrm{B}_{0}$ 11

FIGURA 4 - Esquema do espectrômetro de RPE $-13$

FIGURA 5 - Deformações angulares --a-d 14

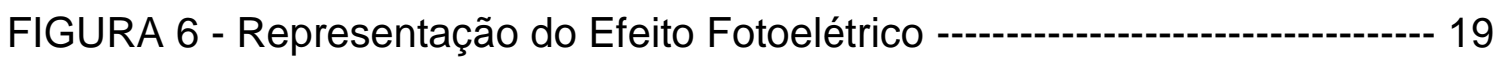

FIGURA 7 - Representação do Efeito Compton ------------------------------- 20

FIGURA 8 - Representação da produção de pares --------------------------------- 21

FIGURA 9 - Esquema dos efeitos da radiação em polímeros de amido ------- 25

FIGURA 10 - Fonte de 60Co Gammacell 220 utilizada nas irradiações-------- 28

FIGURA 11- Equipamento de RPE Bruker, modelo EMX Premium X. -------- 29

FIGURA 12 - Espectroscópico Spectrum 1000 da Perkin-Elmer infravermelho com transformada de Fourier

FIGURA 13 - Comparação dos sinais de EPR de amostras de amido de milho irradiadas com dose de 10 (a) e 20 kGy (b) , 1 dia após a irradiação.

FIGURA 14- - Comparação dos sinais de EPR de amostras de amido de batata irradiadas com dose de 0 (a), 10 (b) e 20kGy (c). 35

FIGURA 15- Comparação dos sinais de EPR de amostras de polvilho azedo irradiadas com dose de 0(a), 10(b) e 20kGy(c), 1 dia após irradiação. $-36$

FIGURA 16 - Sinal de EPR da amostra de amido de milho irradiada com dose de 30kGy. 38

FIGURA 17- Sinal de EPR da amostra de amido de batata irradiada com dose de $30 k G y$.

FIGURA 18- Sinal de EPR da amostra de polvilho azedo irradiado com dose de 30kGy. 
FIGURA 19- Decaimento do sinal de RPE de amido de milho irradiado com dose de 10 kGy.

FIGURA 20 - Decaimento do sinal de RPE de amido de batata irradiado com dose de $10 \mathrm{kGy}$

FIGURA 21 - Decaimento do sinal de RPE de polvilho azedo irradiado com dose de $10 \mathrm{kGy}$.

FIGURA 22- Decaimento do sinal de RPE de amido de milho irradiado com dose de 20 kGy.

FIGURA 23- Decaimento do sinal de RPE de amido de batata irradiado com dose de

20 kGy.

FIGURA 24- Decaimento do sinal de RPE de amido de batata irradiado com dose de

20 kGy.

FIGURA 25- Curva de decaimento do sinal de RPE de amido de milho irradiada com dose de $30 \mathrm{kGy}$.

FIGURA 26- Curva de decaimento do sinal de RPE de amido de batata irradiada com dose de $30 \mathrm{kGy}$.

FIGURA 27- Curva de decaimento do sinal de RPE de polvilho azedo irradiado com dose de $30 \mathrm{kGy}$. 45

FIGURA 28- Espectro FTIR de amido de milho irradiado com dose de 0 e $10 \mathrm{kGy}$ (a) e 0 e 20 kGy (b).

FIGURA 29- Espectros FTIR de fécula de batata irradiada com doses de 0 e 10 kGy (a) e 0 e 20 kGy (b). 52

FIGURA 30 - Espectros FTIR de polvilho azedo irradiado com dose de 0 e 10 kGy (a) e 0 e 20 kGy (b). 53 


\section{INTRODUÇÃO}

O amido é encontrado em grandes quantidades na natureza. É um polímero de glicose, o mais abundante carboidrato de reserva em plantas encontrado em folhas, flores, sementes, talos e raízes. Também é a principal fonte de energia para o homem, compondo $80-90 \%$ de todos os polissacarídeos da dieta humana, e é o principal responsável pelas propriedades tecnológicas que caracterizam grande parte dos produtos processados. O amido é conhecido como alimento e também utilizado em outras aplicações desde muitos séculos. Recentemente, o amido vem se posicionando como material bem aceito pelo consumidor para a preparação de filmes utilizados como embalagem de produtos frescos (GIUGGIOLI, GIRGENTI, PEANO, 2017).

A radiação ionizante é aplicada industrialmente para a realização de ensaios não-destrutivos, modificação de materiais poliméricos, preservação e desinfestação de produtos alimentícios e esterilização de produtos farmacêuticos, médicos e cirúrgicos.

A radiação ionizante é eficiente para inativar micróbios, insetos e parasitas, mas esta tecnologia, mesmo conhecida, é aplicada comercialmente de maneira restrita em produtos alimentícios. No campo das pesquisas, há inúmeros estudos que analisam os efeitos das radiações nos mais variados sistemas que envolvem alimentos (OLIVEIRA, 2009; UEHARA, 2011; TEIXEIRA, 2011; TAKINAMI, 2014). Em particular, OLIVEIRA (2009) utilizou a técnica de ressonância paramagnética eletrônica (RPE) para o estudo de soja irradiada, determinando a estabilidade do sinal produzido por radicais livres gerados pela radiação em função do tempo, verificando se as concentrações de componentes com comportamento antioxidante afetariam a formação dos radicais detectados por RPE e se as concentrações seriam alteradas ou não pela radiação.

A geração de radicais livres em materiais biológicos é fato conhecido que acontece a) por oxido-redução biológica; b) pela ação da radiação ionizante, ultravioleta e visível sobre sistemas biológicos; c) na carcinogênese química (COMMONER, TOWNSEND \& PAKE, 1954); também o efeito da temperatura e a ação mecânica podem estar envolvidas (BIDZIŃSKA, DYREK, WENDA, 2010; LABANOWSKA et al., 2014). 
Certos autores aplicaram Ressonância Paramagnética Eletrônica (RPE) para o estudo, em amidos, de radicais livres gerados mecânica e termicamente (DYREK et al., 1990; BIDZIŃSKA et al., 2010). Os principais efeitos da radiação ionizante sobre os carboidratos presentes nos alimentos são basicamente semelhantes àqueles causados por aquecimento ou outros tratamentos. Estes incluem quebras de cadeias de polissacarídeos, degradação do amido e celulose em açucares simples, a formação de ácidos, cetonas etc, a partir dos monossacarídeos (MURANO, 1995).

A espectroscopia no infravermelho (IV) é uma das mais importantes técnicas instrumentais modernas (GUTIERREZ, TAPIA \& PEREZ, 2015). Pode ser utilizada para trabalhos de rotina (controle de qualidade) bem como, apresenta grande potencial de associação dos espectros obtidos com as estruturas e presença de grupos funcionais.

Este trabalho teve como finalidade o estudo da interação da radiação ionizante em amidos. Para isso utilizou-se duas técnicas instrumentais.

A Espectroscopia Paramagnética Eletrônica (EPR ou RPE) e a Espectroscopia no Infravermelho por Transformada de Fourier ( FTIR). 


\subsection{OBJETIVO}

O objetivo deste trabalho é o estudo de amidos irradiados utilizando a aplicação da ressonância paramagnética eletrônica (RPE) e espectroscopia de Infravermelho por transformada de Fourier. Serão analisadas as modificações decorrentes da ação da radiação ionizante de fonte de ${ }^{60}$ Co e ou feixe de elétrons em amidos naturais e blendas, analisando os espectros de amidos irradiados e verificando o decaimento do sinal ao longo do tempo pós irradiação.

\subsection{Objetivos específicos}

- Registrar e analisar espectros RPE de amidos irradiados

- Verificar o decaimento do sinal de RPE ao longo do tempo pós irradiação.

- Registrar e analisar espectros de FTIR estabelecendo as possíveis mudanças ocorridas por ação da radiação.

\section{REVISÃO DA LITERATURA}

\subsection{Amido}

O amido encontra-se em diversas espécies vegetais como a principal reserva de energia, sendo abundante em grãos de cereais (40\% a $90 \%$ do peso seco), leguminosas (30\% a $50 \%$ do peso seco), tubérculos (65\% a $85 \%$ do peso seco) e frutas imaturas ou verdes (40\% a 70\%) (LAJOLO \& MENEZES, 2006). Ele é também a fonte mais importante de carboidratos na alimentação humana, representando $80 \%$ a $90 \%$ de todos os polissacarídeos da dieta (FAO, 1998; MANN et al., 2007).

Apesar de a dieta humana conter pouca glicose livre, esta aparece em proporções consideráveis como amido, sacarose e lactose. O amido é o mais abundante dos polissacarídeos de armazenamento de energia de plantas, usualmente depositado na forma de grandes grânulos no citoplasma das células. Tais grânulos tem um diâmetro de 100 a $400 \AA$, e consistem em um número de 
moléculas de polissacarídeos em íntima associação, onde podem estar presentes proteínas e enzimas participantes da síntese e degradação dos polissacarídeos. Em cereais como trigo, milho, cevada, centeio e sorgo, os grânulos podem ser classificados como simples, quando cada plastídio contem um grânulo, ou compostos (arroz e aveia) quando muitos grânulos estão dentro de cada amiloplasto (LINDEBOOM et al, 2004; LAJOLO \& MENEZES, 2006). O amido é sintetizado nas folhas, onde serve como carboidrato de reserva temporário, acumulando-se nos cloroplastos durante o dia e servindo como fonte principal para síntese de sacarose citosólica durante a noite. Essa sacarose é então transportada para os órgãos de armazenamento das plantas, como sementes, frutas, tubérculos e raízes (VANPUTTE \& DELCOUR, 2004; TESTER et al., 2004)

A cadeia bioquímica responsável pela síntese de amido envolve moléculas de glicose produzidas nas plantas através da fotossíntese. $O$ amido é sintetizado nas folhas, onde serve como carboidrato de reserva temporário, acumulando-se nos cloroplastos durante o dia e servindo como fonte principal para síntese de sacarose citosólica durante a noite. Essa sacarose é então transportada para os órgãos de armazenamento das plantas, como sementes, frutas, tubérculos e raízes (ALCAZAR-ALAY \& MEIRELES, 2015).

O amido apresenta-se na forma de grânulos, estruturas parcialmente cristalinas. Geralmente grânulos de amido nativos contem $15-50 \%$ de cristalinidade (ROBERTSON \& SUTCLIFFE, 2005). Em cereais como trigo, milho, cevada, centeio e sorgo, os grânulos podem ser classificados como simples, quando cada plastídio contem um grânulo, ou compostos (arroz e aveia) quando muitos grânulos estão dentro de cada amiloplasto.

O amido é digerido no trato digestivo sendo degradado até glicose, que é o açúcar que será afinal distribuído para o tecidos. A digestão de sacarose e lactose origina, além de glicose, frutose e galactose.

Há vários fatores que interferem na digestibilidade do amido, como: disponibilidade de água necessária para a hidrólise das ligações glicosídicas e viscosidade do meio para difusão dos substratos. $O$ amido pode ser classificado em: Amido rapidamente digerível (ARD), amido lentamente digerível (ALD) e amido resistente (AR). O ARD, leva 20 minutos para converte-se em glicose o ALD, leva de 20 a 120 minutos para converte-se em glicose, ALD está 
relacionado com o baixo índice glicêmico. O AR não é convertido em glicose e resiste á ação das enzimas digestivas, sendo seu comportamento semelhante as fibras alimentares. O principal interesse em relação ao AR é o seu papel fisiológico. Por não ser digerido no intestino delgado, este tipo de amido se torna substrato para fermentação de bactérias anaeróbicas no cólon. O consumo de amido resistente (AR) tem sido associado com a prevenção de doenças cardiovasculares, metabólicas e câncer (ASP E BJORF, 1992; KAMAL et al., 2000; LOPEZ e FASCIO, 2004; TOPPING e CLIFTON, 2001), (POLESI, 2004). O AR pode ser adicionado em produtos alimentícios na substituição parcial de farinha de trigo aumentando assim o valor nutritivo do produto (FASOLIN et al., 2007; MAJZOOBI et al., 2014).

O amido de diferentes fontes botânicas têm diferentes estruturas, incluindo o tamanho granular, distribuição de peso molecular e proporção de amilose e a amilopectina (TAB 1).

Amidos de milho e de batata utilizados neste trabalho são oriundos de plantas nativas. A fécula de mandioca fermentada, popularmente chamada de polvilho azedo, é obtida pela fermentação da fécula doce de mandioca e secagem ao sol (CEREDA, 1983 A, B, 1987; CEREDA et al., ASCHERI \& VILELA, 1995; MAEDA \& CEREDA, 2001). As modificações ocorridas durante o processo fermentativo do polvilho azedo são a diminuição do $\mathrm{pH}$, formação de ácidos orgânicos, aumento da acidez titulável, ataque de enzimas amilolíticas, aumento do poder de inchamento, da solubilidade e diminuição da viscosidade do polvilho (ASCHIERI \& VILELA, 1995).

TABELA 1 - Teores de amilose e amilopectina de algumas espécies vegetais

\begin{tabular}{lll} 
Origem & Amilose (\%) & Amilopectina (\%) \\
\hline Mandioca & 17 & 83 \\
Milho & 24 & 76 \\
Batata & 20 & 80 \\
\hline
\end{tabular}

Fonte: Ciacco e Cruz (1982) 
A amilose apresenta molécula menor e é essencialmente linear, enquanto que a amilopectina é uma molécula maior e possui elevado número de ramificações curtas. A amilose e a amilopectina não existem livres na natureza, mas como agregados semi-cristalinos em grânulos de amido. O tamanho, a forma e a estrutura desses grânulos variam, substancialmente, entre as fontes botânicas. Os diâmetros dos grânulos geralmente variam de menos de $1 \mu \mathrm{m}$ a mais do que $100 \mu \mathrm{m}$, e os formatos podem ser regulares (por exemplo: esférico, ovóide ou angular) ou bastante irregulares. A figura abaixo mostra a estrutura de amilose e amilopectina.

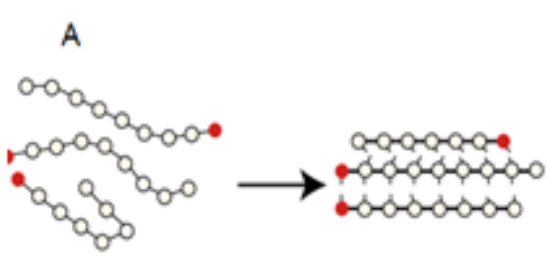

Amilose

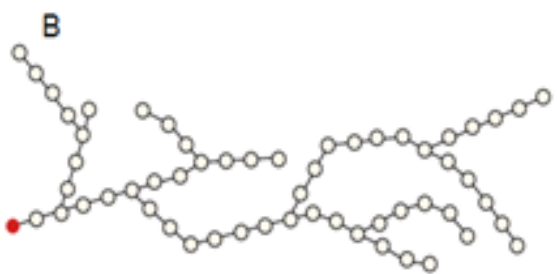

Amilopectina

FIGURA 1 - Estrutura da amilose (A) e amilopectina (B) (imagem retirada do Google imagens)

A Agência Nacional de Vigilância Sanitária (ANVISA), através da Resolução da Comissão Nacional de Normas e Padrões para Alimentos, CNNPA no 12 , de 1978, publicada no D.O de 24/07/1978, define:

Amido é o produto amiláceo extraído das partes aéreas comestíveis dos vegetais (sementes), etc.).

Fécula é o produto amiláceo extraído das partes subterrâneas comestíveis dos vegetais (tubérculos, raízes e rizomas).

Entre os amidos, féculas e derivados mais usuais, incluem-se: i) amido de milho produto amiláceo extraído de milho (Zea mays, L.); ii) fécula de batata - produto amiláceo extraído da batata (Solanum tuberosum, L.); iii) polvilho ou fécula de mandioca - produto amiláceo extraído da mandioca (Manihot utilissima). O polvilho de acordo com o teor de acidez, será classificado em polvilho doce ou 
polvilho azedo. As características físicas e químicas que estes três produtos devem possuir: umidade máxima: $14 \%$ p/p, amido mínimo $80 \%$ p/p e resíduo mineral fixo máximo $0,50 \% \mathrm{p} / \mathrm{p}$. 


\subsection{Ressonância Paramagnética Eletrônica (RPE ou ESR)}

A espectroscopia de ressonância paramagnética eletrônica ou de ressonância de spin eletrônico (RPE, ou EPR, do inglês electron paramagnetic resonance ou ainda ESR, do inglês electron spin resonance) é uma técnica espectroscópica que detecta espécies paramagnéticas:

- Radicais livres no estado sólido, líquido ou gasoso;

- Alguns defeitos pontuais em sólidos;

- Dirradicais;

- Sistemas no estado tripleto (2 elétrons desemparelhados);

- Sistemas com 3 ou mais elétrons desemparelhados;

- A maioria de íons de metais de transição e de terras raras ( WEIL \& BOLTON, 2007).

Através da técnica de RPE, pode-se determinar o número de radicais livres existentes em uma amostra gerados pela ação da radiação ionizante. Os radicais livres produzidos pela radiação em substâncias orgânicas possuem um tempo de vida de picos segundos, meses, séculos. Esta técnica é não destrutiva, específica e combina simplicidade e rapidez (STEVENSON E GRAY, 1995), (RAFFI E STOCKER, 1996) (DESROSIERS, 1996).

Nos radicais livres e outras espécies paramagnéticas, os spins estão desemparelhados, existindo em quaisquer destes estados ( $\uparrow$ ou $\downarrow$ ). $\bigcirc$ spin, ou momento angular intrínseco, é uma propriedade de todas as partículas elementares. A manifestação mais obvia do spin é o fato do elétron possuir um momento magnético ( $\mu$ e), como uma esfera carregada que girasse em torno de seu próprio eixo, embora o valor de $\mu$ e não corresponda exatamente a essa situação (ATHERTON, 1993).

A aplicação da técnica de RPE consiste em provocar uma transição entre esses estados, através da excitação da amostra com um feixe de fótons com energia igual a diferença entre os dois níveis, assim aplica-se um campo magnético externo $B_{0}$ para provocar essa transição.

O campo magnético, $\mathrm{B}_{0}$, produz dois níveis de energia para o momento magnético do elétron. O elétron não emparelhado terá um estado de menor energia quando o momento do eléctron é alinhado com o campo magnético e 
uma fase de alta energia quando está alinhada contra o campo magnético. Os dois estados são rotulados pela projeção do spin do elétron, ms, na direção da campo magnético. Como o elétron é uma partícula de spin $1 / 2$, o estado paralelo é designado como $\mathrm{ms}=+1 / 2$ e o estado antiparalelo é $\mathrm{ms}=-1 / 2$ (FIG 2 e FIG 3). A energia de cada orientação é o produto de $\mu$ e $B_{0}$. Para um elétron $\mu=m_{s} g_{e} \beta$, onde $\beta$ é uma constante de conversão chamado o magneto de Bohr e g fator espectroscópico do elétron livre e igual a $2,0023192778(\approx 2,00)$. Portanto, as energias para um elétron com $m s=+1 / 2$ e $m s=-1 / 2$ são, respectivamente $\mathrm{E}_{\frac{1}{2}}=\frac{1}{2} \mathrm{~g}_{\mathrm{e}} \beta \mathrm{B}_{0} \mathrm{E}_{\frac{1}{2}}=-\frac{1}{2} \mathrm{~g}_{\mathrm{e}} \beta \mathrm{B}_{0}$ Como resultado, existem dois níveis de energia para o elétron em um campo magnético.

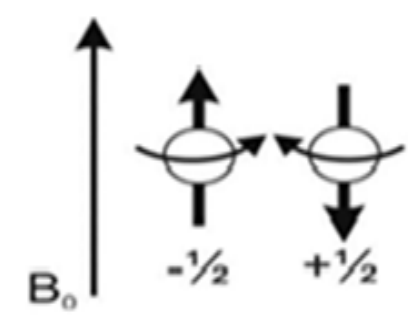

FIGURA 2 - Mínimo e Máximo de energia de orientações respeito ao campo magnético $\mathbf{B}_{\mathbf{0}}$ (Fonte: DUIN, 2011).

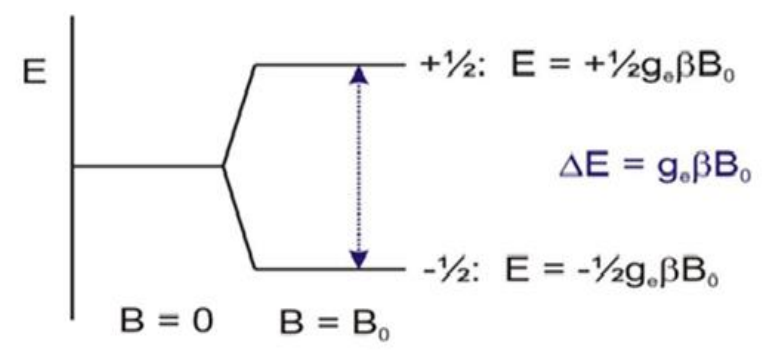

FIGURA 3 - Indução das energias do estado de rotação como função do campo magnético $\mathbf{B}_{\mathbf{0}}$ (Fonte: DUIN, 2011). 


\subsubsection{RPE Interação hiperfina}

A estrutura hiperfina é o desdobramento das linhas de ressonância em várias componentes e ela identifica a estrutura do espectro que pode ser atribuida á interação magnética do spin do elétron com os núcleos. A fonte da estrutura hiperfina dos espectros de RPE é a interação magnética do spin do elétron com os momentos de dipolo magnéticos dos núcleos do radical. A estrutura hiperfina de um espectro de RPE é uma espécie de impressão digital que ajuda a identificar os radicais presentes na amostra.

\subsubsection{Efeito Zeeman}

No Efeito Zeeman a ação do campo magnético externo provoca o desdobramento das linhas espectrais de um átomo. Este fenômeno foi investigado sem sucesso por Faraday, previsto por Lorentz com base na teoria clássica e observado pela primeira vez por Zeeman (TIPLER e LLEWELLYN, 2014).

Pieter Zeeman (1865-1943), físico holandês descobre o Efeito Zeeman que contribuiu para o conhecimento da estrutura atômica. Zeeman compartilhou o prêmio Nobel de física de 1902 com seu professor H. A . Lorentz pela descoberta (TIPLER e LLEWELLYN, 2014).

\subsubsection{Aplicação da técnica de RPE}

A espectroscopia de RPE encontra importantes aplicações em dosimetria (GOMEZ et al., 2011, datação (HAN et al., 2017) e na área de materiais (RHODES, 2011; CAMPBEL et al., 2015; LY \& BASKO, 2016).

Estudos por RPE de material biológico submetido à irradiação já são conhecidos há meio século, mas só a partir de 1985 foi utilizado como método de detecção em carne, frutas e frutos do mar irradiados (LEAL et al., 2004).

Atualmente, há uma quantidade significativa de resultados da aplicabilidade da RPE em diversos grupos de alimentos (DUARTE et al., 1995; SCHRAMM et al., 1996; DELINCÉE, 2002), como método de detecção de irradiação, existindo já normas européias para aplicação de RPE na detecção de 
especiarias irradiadas por irradiação gama (EN Protocol EN 1786, 1997; EN Protocol EN 1787, 2000; EN Protocol EN 13708, 2001).

O experimento convencional de RPE consiste em detectar a absorção de micro-onda de uma amostra em função do campo magnético aplicado passando pela condição de ressonância do sistema. A micro-onda numa determinada frequência, normalmente gerada por uma klystron ( gerador de micro-ondas), incide sobre a amostra por meio de um guia de onda, que conecta a klystron a uma cavidade ressonante onde se posiciona a amostra. Em seguida, o computador faz a leitura do espectro relacionado a amostra irradiada.

A espectroscopia por RPE é considerada umas das mais importantes formas de se detectar radicais livres em alimentos. Estima-se que uma dose de $10 \mathrm{kGy}$ gera para cada quilograma de alimentos, cerca de $5 \cdot 10^{-3} \mathrm{~mol}$ de radicais livres (GLIDWELL et al.,1993). A detecção é sincronizada com uma modulação do campo magnético, que tem portanto uma componente contínua (CC) e uma alternada (CA) de amplitude muito menor que a CC. Essa detecção modulada leva na prática à obtenção de espectros que correspondem à derivada da curva de absorção em relação ao campo CC. Medidas com variação angular da posição da amostra em relação ao campo magnético, e variando a temperatura da amostra, são utilizadas para a determinação de uma série de parâmetros extrínsecos e intrínsecos (PIRES, 2006). A FIG 4 apresenta um esquema de sistema de detecção de sinal de RPE. 


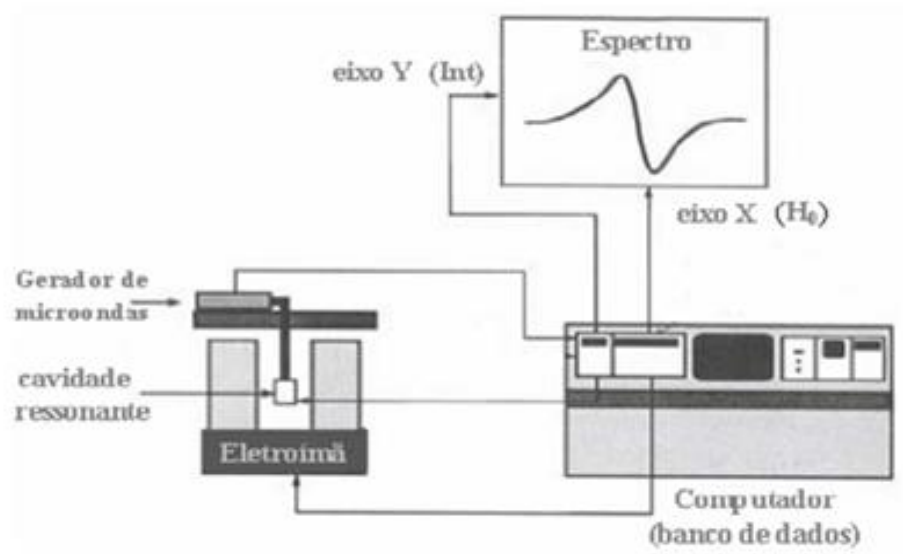

FIGURA 4 - Esquema do espectrômetro de RPE (Fonte: COGO, 2008)

\subsubsection{Parâmetros espectroscópicos}

Importantes parâmetros que influenciam o sinal de EPR. Esses parâmetros são: Intensidade do sinal (I) é obtida a partir da área integrada sob o sinal de absorção, que é proporcional à concentração de spins desemparelhados originando o espectro, ou pela medida pico-a-pico das linhas derivadas (quando a largura de linha, definida abaixo, permanece constante).

Fator-g (g): é utilizado para caracterizar a posição de uma ressonância, sendo bastante útil na identificação de sinais desconhecidos. É obtido a partir da expressão $\mathrm{g}=\mathrm{hv} / \mathrm{pHo}$, com Ho tomado no ponto onde a derivada se anula. $\mathrm{O}$ fator-g para um elétron livre (e também para aqueles encontrados em vários radicais livres) vale 2,0023 (CARRINGTON et al McLACHLAN, 1967.)

Largura de linha $(\mathrm{AH})$ e forma de linha: é normalmente expressa como a metade da largura a meia altura de uma linha de absorção ou como a largura total entre os extremos da cui-va da primeira derivada (largura pico-a-pico). Duas são as razões fundamentais para que uma linha de absorção tenha largura finita e não apareça como uma função delta de altura infinita (WERTZ et al BOLTON, 1972). 


\subsection{Espectroscopia no Infravermelho com Transformada de Fourier (EIVTF ou FITR)}

A espectroscopia na região do Infravermelho do espectro eletromagnético, é um tipo de espectroscopia de absorção vibracional que mede diferentes tipos de vibração entre átomos de acordo com suas ligações interatômicas (FIG 5).
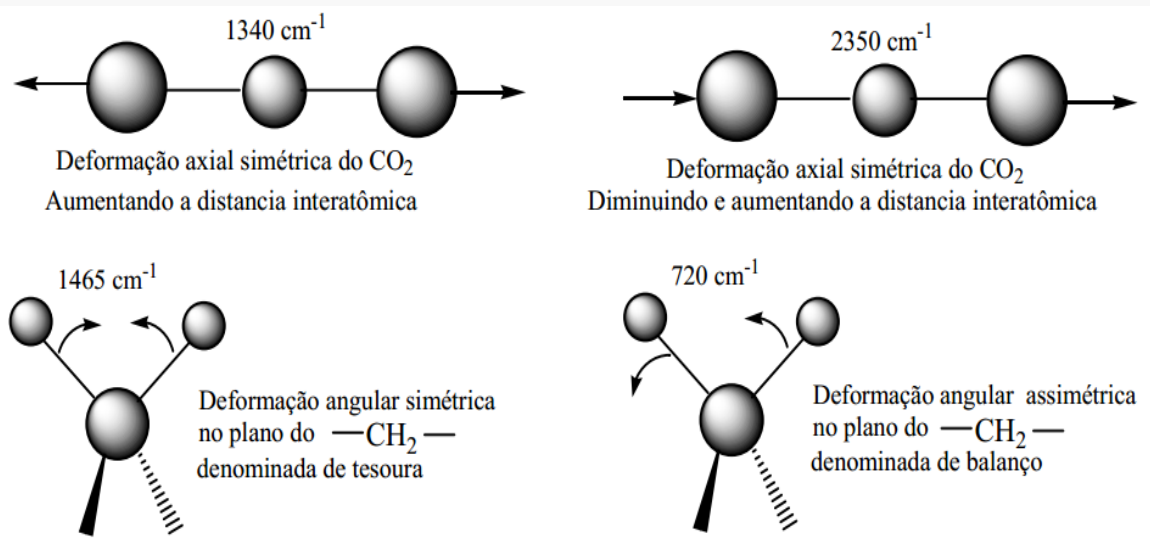

FIGURA 5 - Deformações angulares (Fonte: SOLOMONS, 2005)

A gama de comprimentos de onda que corresponde a região do infravermelho médio (MIR) situa-se entre 4000 a $400 \mathrm{~cm}^{-1}$, indica a zona de maior interesse para a caracterização molecular.

A espectroscopia no infravermelho se baseia no fato de que as ligações químicas das substâncias possuem frequências de vibração específicas, as quais correspondem a níveis de energia da molécula. A espectroscopia de infravermelho produz espectros de absorção ou transmissão fazendo um feixe de luz na região do infravermelho incidir sobre a substância e determinando as frequências absorvidas por ela. Além de líquidos, a espectroscopia pode ser utilizada para examinar gases, como a atmosfera de planetas. A espectroscopia na região do infravermelho é uma técnica importante na análise orgânica qualitativa, sendo amplamente utilizada nas áreas de química de produtos naturais, síntese e transformações orgânicas (LOPES \& FASCIO, 2004). É possível a aplicação a amostras em estado sólido amorfo ou cristalino, soluções aquosas, solventes orgânicos, filmes, pastilhas de $\mathrm{KBr}$ e membranas Assim como qualquer técnica espectroscópica, a espectroscopia no IV é devida à 
interação da radiação, no caso IV, com a matéria, e ocorre com o acoplamento do campo elétrico oscilante da vibração molecular e o da radiação incidente. A faixa de radiação do infravermelho, no espectro eletromagnético, ocorre na faixa entre o visível e micro-ondas, sendo que a faixa de maior interesse se encontra na região de 4000 a $400 \mathrm{~cm}$ (MANTSCH \& CHAPMAN, 1995).

$\mathrm{Na}$ espectroscopia no infravermelho por transformada de Fourier (no Inglês Fourier transform infrared, FTIR), os espectrofotómetros FTIR têm como base o interferômetro de Michelson. A FTIR é uma técnica de análise para colher o espectro infravermelho mais rapidamente. Em vez de se coletar os dados variando-se a frequência da radiação infravermelha, a radiação IV (com todos os comprimentos de onda da faixa usada) é guiada através de um interferômetro. Depois de passar pela amostra o sinal medido é o interferograma. A fonte luminosa utilizada pode ser lâmpadas de halogénio, quartzo ou LEDs. Realizando-se uma transformada de Fourier no sinal resulta-se em um espectro idêntico ao da espectroscopia IV convencional (dispersiva).

Neste sistema a radiação da fonte luminosa é dividida em dois feixes iguais através de um beamsplitter (divisor de feixes). Um dos feixes segue em direção a um espelho de posição fixa no qual reflete de volta ao divisor de feixes, e aqui volta a dividir-se e parte desta vai para o detector. O outro feixe parte do beamsplitter em direção ao espelho móvel, este espelho também reflete, ocorrendo nova divisão e parte da radiação segue também para o detector, conseguindo assim, com rapidez percorrer todos os comprimentos de onda em estudo. Á medida que o espelho móvel percorre determinada distância um interferograma é formado com a recombinação dos dois feixes. Deste modo, um interferograma é formado pela soma de todas as ondas de diferentes amplitudes e frequências que chegam ao interferômetro. Com á introdução de espectrômetros de infravermelho com transformada de Fourier (FTIR) melhorou a qualidade dos espectros no infravermelho e minimizou o tempo necessário para obtenção de dados (BRACEWELL,1972).

A informação do interferograma, é descodificada pelo cálculo da Transformada de Fourier, por ação de um microprocessador acoplado ao espectrofotómetro, permitindo obter a distribuição de energia absorvida pela amostra ou pelo espectro da amostra por cada comprimento de onda. $O$ algoritmo das Transformadas de Fourier permite decompor a intensidade da 
energia luminosa do interferograma $(y)$, na soma deas funções senos e co-senos da frequência da radiação luminosa $(x)$ e na velocidade de deslocação dos

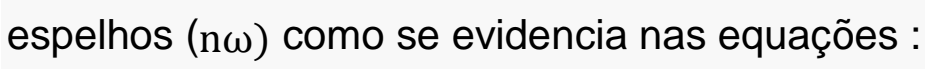

$$
\begin{aligned}
y=a_{0 \sin }(o \omega x) & +b_{0 \cos (o \omega x)+a_{1} \sin (1 \omega x)+b_{1} \cos (1 \omega x)+\cdots} \\
& =\sum_{n-0}^{\infty}\left[a n \sin (n \omega x)+b_{n} \cos (n \omega x)\right] \text { em que } \omega \\
& =\frac{2 \pi}{x_{2}-x_{1}} \text { e } x_{2}-x_{1} \text { é o intervalo das abcissas. }
\end{aligned}
$$

Os métodos de análise multivariada são assim chamados, pois, no caso em que se empregam técnicas espectroscópicas no infravermelho, é possível manipular dados de absorbância espectral associados a mais de uma frequência ao mesmo tempo. Estes métodos têm tornado possível modelar propriedades químicas e físicas de amostras a partir de dados espectroscópicos (WIILIAMS et al., 1987).

As análises qualitativas e quantitativas utilizando espectroscopia na região do infravermelho expandiram-se a partir do momento em que os dados gerados por um espectrofotômetro FTIR pudessem ser digitalizados, habilitando os métodos estatísticos na resolução de problemas de análise química.

Nos métodos clássicos de análise univariável, somente a absorbância de uma frequência é associada á concentração, enquanto que métodos que usam simultaneamente duas os mais frequências são conhecidos como métodos multivariáveis. A precisão dos métodos univariáveis é dependente da capacidade para identificar uma única banda isolada para cada componente. Os métodos multivariáveis, entretanto, podem ser utilizados igualmente quando estão sobrepostas informações espectrais de vários componentes através de várias regiões espectrais selecionadas (BIGGS et al., 1987).

Uma das importantes propriedades de um espectrômetro é a sua resolução, isto é, sua habilidade para distinguir-se entre vizinhança de regiões espectrais. Esta habilidade para decidir vizinhança de bandas estaria relacionada à largura da faixa espectral expressa em unidades de número de onda $(\Delta v)$ ou comprimento de onda $(\Delta \lambda)$. 
Os espectros no infravermelho de compostos químicos poliatómicos covalentes são extremamente complexos, pois são constituídos por inúmeras bandas de absorção, que revelam a natureza das interações entre as moléculas e sua vizinhança, dado que a frequência e a absortividade provocadas por uma determinada ligação química denunciam pequenas alterações quando se altera sua vizinhança.

Os espectros no infravermelho de compostos químicos poliatómicos covalentes são extremamente complexos, pois são constituídos por inúmeras bandas de absorção, que revelam a natureza das interações entre as moléculas e sua vizinhança, dado que a frequência e a absortividade provocadas por uma

A transformada de Fourier no infravermelho (FTIR) e outros métodos foram já utilizados para caracterização e classificação de amostras de amido irradiados. As alterações bioquímicas, devido à irradiação foram detectadas usando as duas técnicas espectroscópicas vibracionais, e análise de variáveis canónica (CVA) foi aplicada aos dados espectrais para discriminar amostras de amido com base na amplitude de irradiação. O O-H $\left(3000-3600 \mathrm{~cm}^{-1}\right)$ alongamento, $\mathrm{C}-\mathrm{H}\left(2800-3000 \mathrm{~cm}^{-1}\right)$ de estiramento, o modo de vibração do esqueleto da ligação glicosídica (900-950 $\left.\mathrm{cm}^{-1}\right)$, em ambos os espectros Raman e de infravermelhos, e a banda de infravermelhos de água adsorvida nas partes amorfas de amidos (1550-1750 $\mathrm{cm}^{-1}$ ) analisados conforme descrevem alguns autores (RAMAZAN et al.,2002). Esses autores concluíram que os dados espectrais relacionados a água adsorvida na região não cristalina de amidos fornece uma melhor classificação de amidos irradiados. Outros autores também analisaram as mudanças no espectro infravermelho devido a modificações conformacionais e mudanças de solvatação do grânulo de amido (RUBENS et al.,1999). DEMIATE et al., (2000) consideram que haveria uma relação entre a estrutura química de amidos determinada por FTIR e certas propriedades funcionais dos amidos. 


\subsection{Interação da radiação com a matéria}

$\mathrm{Na}$ faixa de energias que inclui os raios $\mathrm{X}$ e gama, há várias interações possíveis com o átomo ou com elétrons atômicos ou ainda com o núcleo, mas há também a possibilidade de não-interação, ou seja, a interação da radiação eletromagnética (REM) pode atravessar distâncias consideráveis em um meio material sem modificá-lo e sem se modificar. As probabilidades de interação (e de não-interação) dependem de características do meio e da radiação. A REM ionizante é tratada, em boa parte dos casos, como um conjunto de partículas os fótons. A cada energia de fóton hv corresponde um momento associado hv / c, e, dessa forma, podem ocorrer 'colisões' em que o fóton transfere energia e momento para outras partículas (YOUSHIMURA, 2009). As principais interações que ocorrem na matéria com fótons de energias na faixa de poucos keV até dezenas de MeV são:

- espalhamento coerente (ou efeito Rayleigh): corresponde à absorção e re-emissão da radiação pelo átomo, em uma direção diferente da de incidência. Somente neste efeito a radiação é tratada como onda; em todos os outros se considera a REM como constituída de fótons;

- efeito fotoelétrico: o fóton é absorvido pelo átomo e um elétron atômico é liberado para se mover no material. A energia cinética adquirida por esse elétron é a diferença entre a energia do fóton e a energia de ligação do elétron ao átomo (FIG 6);

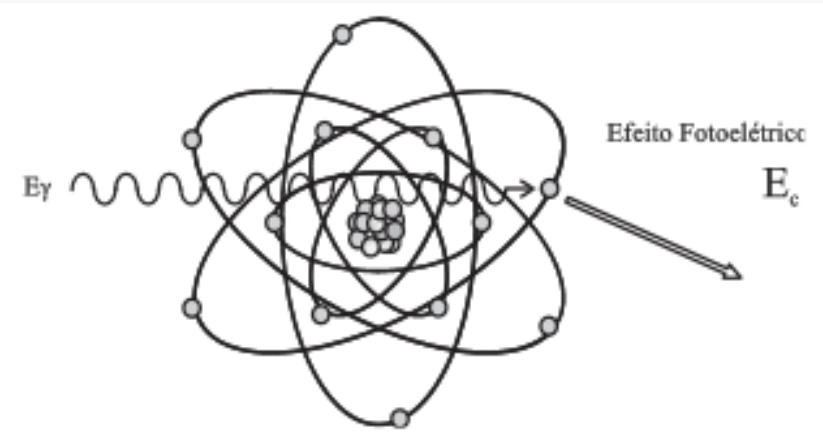

Figura 6 - Representação do Efeito Fotoelétrico (Google imagens)

- efeito Compton (ou espalhamento inelástico): trata-se do espalhamento de um fóton por um elétron livre do material. Há transferência de parte da 
energia e do momento do fóton para o elétron, e um fóton com a energia restante é espalhado em outra direção (FIG 7).

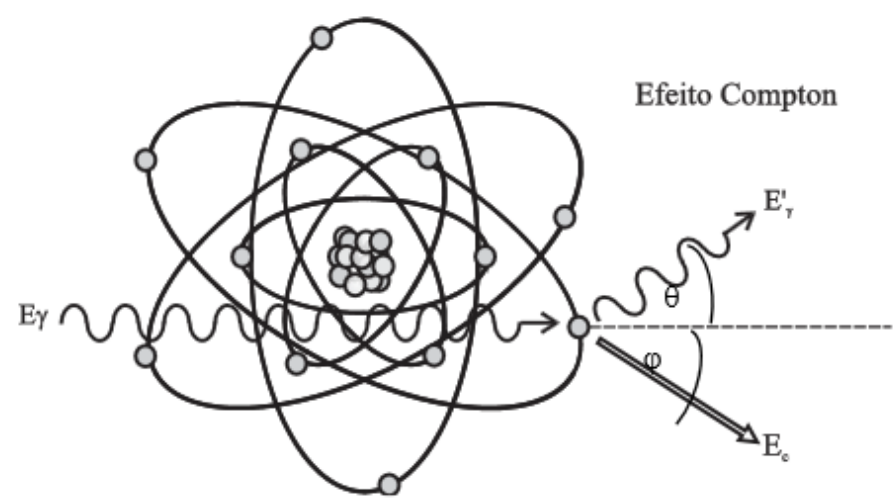

Figura 7 - Representação do Efeito Compton (Google imagens)

- produção de pares elétron-pósitron: Neste processo (FIG 8), o fóton é absorvido e toda sua energia é convertida em massa de repouso e energia cinética de um par partícula/antipartícula - elétron/pósitron. É interpretada como a transição de um elétron de um estado de energia total negativa para um estado de energia total positiva; a diferença de energia entre os dois estados é a energia do fóton incidente, que é absorvido; a lacuna de um elétron no conjunto de estados de energia negativa é observada como um pósitron. É possível a criação de outros pares de partícula/antipartícula, mas a energia necessária do fóton é muito mais elevada. $O$ efeito é resultado da interação entre o fóton e o campo eletromagnético, e ocorre normalmente nas vizinhanças do núcleo, podendo também acontecer devido à interação do fóton com o campo de qualquer partícula carregada, incluindo os elétrons atômicos. Neste caso particular, um elétron atômico também é ejetado e o efeito é chamado de produção de tripleto. É mais provável quanto mais intenso for o campo; 


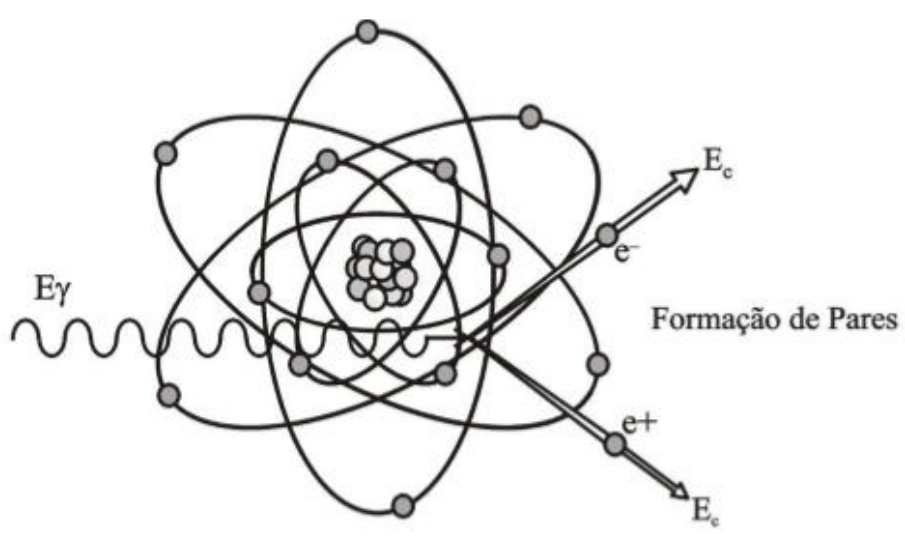

Figura 8 - Representação da produção de pares (Google imagens)

- reações fotonucleares: a principal reação nuclear provocada por fótons é a fotodesintegração, que equivale a um 'efeito fotonuclear' num paralelo com o efeito fotoelétrico. $O$ fóton com energia maior que a energia de ligação de núcleons é absorvido pelo núcleo que libera um próton ou um nêutron com energia cinética suficiente para abandonar o núcleo, que se transforma em outra espécie nuclear. $O$ fóton é absorvido nos processos de efeito fotoelétrico, produção de par e reações fotonucleares.

\subsubsection{Efeitos da radiação ionizante em produtos alimentícios}

A radiação é considerada ionizante se for capaz de arrancar um elétron de um átomo ou de uma molécula, caso contrário, é considerada não ionizante. Quando um elétron é ejetado de um átomo, forma-se o par íon positivo - íon negativo (elétron). $O$ termo radiação ionizante refere-se a partículas capazes de produzir ionização em um meio, sendo diretamente ionizantes as partículas carregadas, como elétrons, pósitrons, prótons, partículas $\alpha$, e indiretamente ionizantes as partículas sem carga, como fótons e nêutrons (OKUNO e YOSHIMURA, 2010).

O emprego da radiação ionizante na área alimentícia foi proposta considerando aspectos da conservação dos alimentos há mais de um século, de início para cereais e seus produtos, com raios alfa $(\alpha)$, beta $(\beta)$ e gama $(\gamma)$ 
provenientes de rádio ou outras substancias radioativas (APPLEBY \& BANKS, 1905).

Para a Organização Mundial da Saúde (WHO, 1999), a irradiação de alimentos é uma técnica que pode ser utilizada com segurança no controle dos mais sérios problemas relacionados com os alimentos: as perdas provenientes da deterioração e as doenças que podem ser ocasionadas pelo consumo de alimentos contaminados pro micro-organismos patogênicos (KAMAT 2005). Por outro lado, pela sua capacidade de eliminar insetos e outras pragas, a irradiação oferece uma importante alternativa ao uso de produtos químicos como meio de atender os requerimentos quarentenários para a desinfestação de "commodites" para o comércio internacional.

Em 1981, um comitê conjunto de especialistas em Salubridade de Alimentos Irradiados da Organização das Nações Unidas para a Agricultura e Alimentação (FAO), da Agência Internacional de Energia Atômica (IAEA) e da Organização Mundial da Saúde (WHO) concluiu que a irradiação de qualquer produto alimentício com dose média total de $10 \mathrm{kGy}$ não oferecia qualquer risco toxicológico ou problema de ordem microbiológica ou nutricional. Entretanto, num relatório de especialistas convocados pelas FAO/IAEA/WHO para estudar o efeito de altas doses de irradiação, conclui-se que alimentos irradiados com doses acima de 10 kGy não causam nenhum risco de saúde para os consumidores (WHO,1999).

O tratamento por irradiação é uma das alternativas de conservação de alimentos, já que não afeta de maneira adversa a qualidade do alimento.

As radiações recomendadas (Codex, 2003) para aplicação em alimentos são:

- Raios gama de ${ }^{60} \mathrm{Co}\left(\mathrm{T}_{1 / 2}: 5,263\right.$ anos; $\beta^{-}: 0,314 \mathrm{MeV} ; \gamma: 1,173$ e 1,332MeV) e

- Raios gama de ${ }^{137} \mathrm{Cs}\left(\mathrm{T}_{1 / 2:} 30\right.$ anos; $\beta-: 0,514$ e 1,176MeV, que decai a $\left.{ }^{137 \mathrm{~m}} \mathrm{Ba}, \mathrm{T}_{1 / 2:} 2,554 \mathrm{~min} . ; \gamma: 0,662 \mathrm{MeV}\right)$;

- Feixe de elétrons de até $10 \mathrm{MeV}$;

- Raios X de até $5 \mathrm{MeV}$. 
No Brasil, a primeira legislação sobre o emprego da radiação ionizante como processo de conservação foi estabelecida através do Decreto-Lei № 72,718 , de 29 de agosto de 1973. As portarias no 09 de 8 de março de 1985 e no 30 de 25 de setembro de 1989, aprovadas posteriormente pela Divisão de Vigilância Sanitária de Alimentos, foram revogadas pela Resolução RDC nำ 21 de 26 de janeiro de 2001, da Agencia Nacional de Vigilância Sanitária -ANVISA. Essa legislação é considerada avançada na área internacionalmente. Tendo como base as conclusões a que chegou o grupo de estudo formado pela FAO/IAEA/WHO (WHO, 2001), a legislação brasileira aprova o uso da radiação em qualquer alimento com qualquer dose, desde que sejam observadas as seguintes condições:

a) a dose mínima absorvida deve ser suficiente para alcançar a finalidade pretendida;

b) a dose máxima absorvida deve ser inferior aquela que compromete as propriedades funcionais e/ou atributos sensoriais dos alimentos;

c) a embalagem deve ter condições higiênicas aceitáveis para o processo de irradiação e

d) o rótulo do produto deve conter os dizeres "ALIMENTO TRATADO POR IRRADIAÇÃO".

\subsubsection{Efeito da Irradiação em amidos}

A aplicação da radiação ionizante (gama e feixe de elétrons) gera radicais livres que são capazes de induzir alterações moleculares e fragmentação de amido (CIESLA et al., 1991; GRANT e D`APPOLONIA, 1991; SABULARSE et al., 1991; SOHKEY e HANNA, 1993). Esta propriedade única seria um dos principais mecanismos subjacentes nas alterações físico-químicas em alimentos ricos em amido, como a redução da viscosidade e alta solubilidade em água (BAO e CORKE, 2002; LEE et al., 2003).

Um dos mais importantes efeitos causados em carboidratos é a quebra da cadeia glicosídica. Em amidos, pectinas e celulose essa quebra resulta na formação de unidades menores de carboidratos. 
Nos amidos, a ruptura da cadeia glicosídica (despolimerização) leva à formação de dextrinas de vários comprimentos de cadeia polimérica e de outros produtos radiolíticos. Geralmente, todos os amidos mostram alterações semelhantes após a irradiação. Outros efeitos: mudança na solubilidade, alteração do pH em solução, descoloração e mudanças nas propriedades da superfície (sensação pegajosa, por exemplo). Podem-se estudar várias características físicas e químicas do amido, como por exemplo: gelatinização, solubilidade, viscosidade, cristalização, degradação, digestabilidade e depolimerização.

É um fato conhecido que o processamento de macromoléculas pela radiação leva à formação de produtos radiolíticos que conduzem à degradação, agregação ou reticulação (FIG 9).

Como descrito acima, a interação da radiação com as macromoléculas de amido leva a quebra da estrutura polimérica. Isso é consequência da produção de radicais livres e moléculas excitadas, pois os radicais livres são particularmente reativos. O elétron desemparelhado pode ser transferido para outra molécula, formando um novo radical. As ligações do radical livre podem também ser quebradas causando a sua decomposição; dois radicais livres podem se combinar entre si e a adição de um radical livre a uma molécula neutra pode originar um radical maior que por sua vez, pode se combinar posteriormente (MASTRO, 1989). Também, como mencionado anteriormente, outros fatores químicos e mecânicos podem induzir a formação de radicais livres, assim como a presença de pequenas quantidades de outros produtos. 

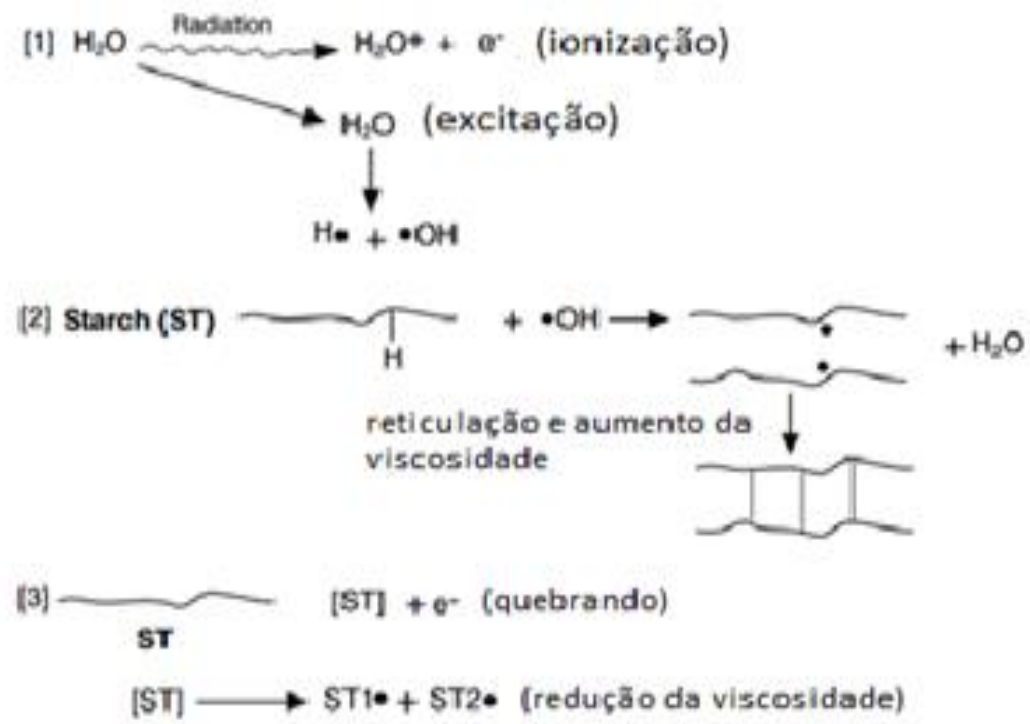

FIGURA 9 - Esquema dos efeitos da radiação em polímeros de amido (Fonte: BHAT\& KARIM, 2009).

Alguns dos principais produtos radiolíticos de moléculas de hidratos de carbono são o ácido fórmico, o acetaldeído e formaldeído. RAFFI et al. (1981) relataram que todos os produtos finais radiolíticos formados com amido irradiado são semelhantes, independentemente da fonte a partir da qual eles são obtida (milho, batata, trigo ou arroz). 


\section{MATERIAL E MÉTODOS}

\subsection{Material}

Amidos comestíveis: fécula ou amido de milho (cereal), batata (tubérculo) e mandioca (raiz) fermentada, conhecido como polvilho azedo, adquiridos no comércio local. Conforme a legislação brasileira, já mencionado, as amostras contém umidade máxima: $14 \%$ p/p, amido mínimo $80 \%$ p/p e resíduo mineral fixo máximo $0,50 \% \mathrm{p} / \mathrm{p}$.

\subsection{Métodos}

\subsubsection{Irradiações}

As amostras dos amidos foram irradiadas numa fonte Gamacell 220 (AECL) de cobalto-60 (FIG 10) localizada no Centro de Tecnologia das radiações, CTR, IPEN. As doses utilizadas nas irradiações foram: 10, 20 e 30 $\mathrm{kGy}$ taxa de dose $\approx 1 \mathrm{kGy}$ h-1.Foram feitas 10 á 12 medições após a irradiação para cada amostra, no caso do RPE. As medições no RPE foram realizadas adequadamente conforme disponibilidade de uso do equipamento e agendamento. Algumas medições foram 1 hora, 2 horas ou até 1 dia após a irradiação.

As massas foram medidas e padronizadas que corresponde as quantidades: massa do Polvilho azedo $(0,0437 \mathrm{~g} \pm 0,0001) \mathrm{g}$; massa do amido de milho $(0,0358 \pm o, o o o 1) g$; massa da fécula de batata $(0,0418 \pm 0,0001) \mathrm{g}$.

Após a irradiação as amostras foram armazenadas em recipiente de isopor até medição. 


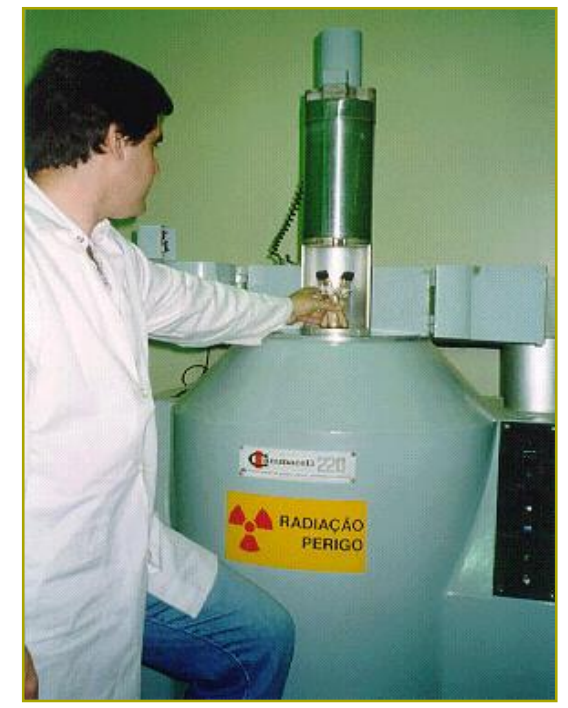

FIGURA 10 - Fonte de ${ }^{60}$ Co Gammacell 220 utilizada nas irradiações

\subsubsection{Espectrometria por RPE}

Para fazer as medições, foi utilizado equipamento Marca Bruker, modelo EMX Premium (FIG 11) localizado no GMR do IPEN.. Foi analisado o comportamento do sinal ao longo do tempo em amostras irradiadas em diferentes doses. Os espectros de RPE foram obtidos á temperatura ambiente. Para as medidas, as amostras foram colocadas em tubos de quartzo de $3 \mathrm{~mm}$ de diâmetro.

Os parâmetros utilizados no equipamento RPE foram:

- Amplitude de Modulação de 2 Gauss

- Potência de microondas $10 \mathrm{~mW}$

- 10 scaners

- Freqüência de Modulação de 100 kHz.

- Frequência de Ressonância : 9,853 GHz

- Tempo de varredura : 10s 


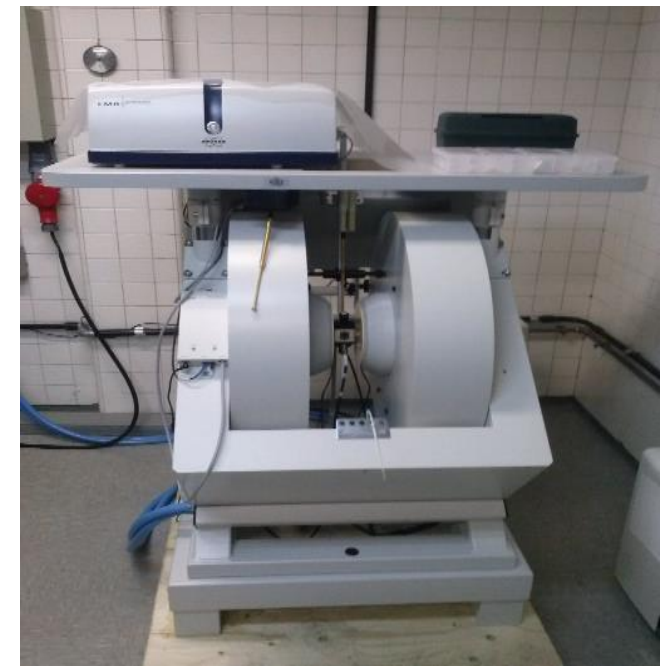

FIGURA 11 - Equipamento de RPE Bruker, modelo EMX Premium X. (Foto: SILVA, G.D., em 2/7/2014).

O programa Origin pro 8 foi utilizado para obtenção das equações e curvas de decaimento e o sinal gerado por cada amido. Os espectros de FITR também foram obtidos utilizando o mesmo programa.

Para obtenção das medições foi seguido o seguinte procedimento:

1. 3 amostras foram irradiadas com a mesma dose e taxa de dose

2. As condições ambientais foram as mesmas para as 3 amostras

3. A posição das amostras na cavidade foi fixada para assim se manter o padrão de reprodutibilidade das medições

4. Para cada amostra foi realizado 10 escaneamentos realizado no equipamento de EPR

5. Os parâmetros do equipamento tais como, potencia de micro-ondas, amplitude de modulação, frequência de modulação e frequência de ressonância, foram fixados em todos os experimentos.

Para a determinação do Fator g, foi utilizada como equação base

$$
\mathrm{g}=714,4775 . v(\mathrm{GHz}) / \mathrm{B}_{\mathrm{O}} \text { (Gauss) }
$$

Onde o valor de 714,775 foi calculado utilizando os valores teóricos acima mencionado (Magneto de Bohr $\left(\mu_{\mathrm{B}}\right)$, Constante de Planck (h) $\left(6,626.10^{-34} \mathrm{~J} . \mathrm{s}\right.$, Campo Magnético em Tesla $(\mathrm{T})$, Frequência de microondas (v), em Hertz $(\mathrm{Hz})$ 
$\mathrm{Na}$ equação reduzida do fator $\mathrm{g}$ utilizamos o valor do campo magnético em Gauss ( $G$ ) e a frequência de microondas em $\mathrm{GHz}$ ( Gigahertz). A frequencia de ressonancia utilizada foi $v=9,84985 \mathrm{GHz}$ ( DSC).

\subsubsection{Espectroscopia no infravermelho (FTIR)}

A técnica foi aplicada no modo transmissão (ATR). Foi utilizado espectrômetro Perkin Elmer modelo Spectrum 1000 com transformada de Fourier localizado no CTR do IPEN-CNEN/SP (FIG 12). Os espectros de FITR em transmitância foram obtidos utilizando o programa Origin pro 8 na faixa de 4000 a $400 \mathrm{~cm}^{-1}$ do infravermelho após 16 varreduras, e utilizado esquema para interpretação de espectros de substâncias orgânicas na região do infravermelho descrito por Lopes e Fascio (2004).

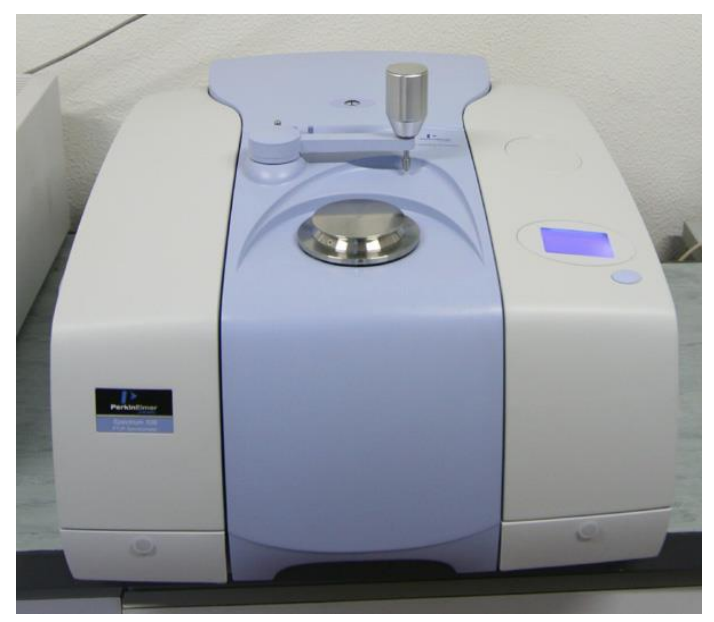

Figura 12 - Espectrofotômetro Spectrum 1000 da Perkin-Elmer infravermelho com transformada de Fourier. 


\section{RESULTADOS E DISCUSSÃO}

\subsection{Espectroscopia de EPR}

Foram registrados os espectros de EPR dos amidos irradiados. Amostras não irradiadas de amido de milho não apresentaram sinal de RPE. Entretanto, amostras não irradiadas de amido de batata e de polvilho azedo apresentaram sinal significativo de singleto centrado em $\mathrm{g} \approx 2.0$. Este sinal pode ser atribuído a outros fatores ou produtos vegetais, além de amido, presentes nas amostras.

Também, esse sinal de fundo poderia ser entendido como decorrente de que no processo de fabricação destes amidos ocorreram a formação de radicais de longa duração, seja por efeito térmico, químico ou físico.

Para estabelecer o fator-g, foram utilizadas as 10 primeiras medições e depois a 10 últimas medições na dose de 10 kGy da amostra de amido de milho. $\mathrm{Na}$ TAB 2 se encontram os valores calculados de $\mathrm{g}$.

TABELA 2 - Valores de fator-g ( experimental)

\begin{tabular}{ll}
$\begin{array}{l}\text { Campo } \\
\text { magnético } \\
\left(\boldsymbol{B}_{\boldsymbol{O}}\right)(\mathrm{G})\end{array}$ & $\begin{array}{c}\text { Fator } \mathrm{g} \\
\text { (experimental) }\end{array}$ \\
\hline 3415,3 & 2,06062 \\
3415,5 & 2,06037 \\
3415,7 & 2,06025 \\
3415,9 & 2,06013 \\
3416,1 & 2,06001 \\
3416,3 & 2,05989 \\
3416,5 & 2,05977 \\
3416,7 & 2,05965 \\
3416,9 & 2,05953 \\
3417,1 & 2,05941 \\
3613,3 & 1,94759 \\
3613,5 & 1,94748 \\
3613,7 & 1,94737 \\
3613,9 & 1,94727 \\
3614,1 & 1,94715 \\
3614,3 & 1,94705 \\
\hline 3614,5 & 1,94694 \\
\hline 3614,7 & 1,94683 \\
\hline 3614,9 & 1,94672 \\
\hline 3615,1 & 1,94661 \\
\hline & \\
\hline Média & $\mathbf{2 , 0 0 3 5 3 2}$ \\
& $\mathbf{0} \mathbf{0 5 7 8 9}$ \\
\hline
\end{tabular}


Analisando os valores experimentais do fator $\mathrm{g}$ com o valor teórico para um elétron livre que vale 2,0023, verificamos que houve uma variação a partir da $3^{\text {a }}$ casa decimal nas 10 primeiras medições. Depois nas 10 últimas percebe-se uma variação nas primeiras casas variando para 1,944. Esses valores estão dentro do esperado com o tipo de material empregado (SLICHTER, 1990 et al CARRINGTON, McLACHLAN, 1967).

Nas FIG 13, 14 e 15 são apresentadas comparações dos espectros de RPE de amostras de amido de milho, batata e polvilho azedo, irradiadas com doses de 10 e 20 kGy, registrados 1 dia após irradiação.

a)

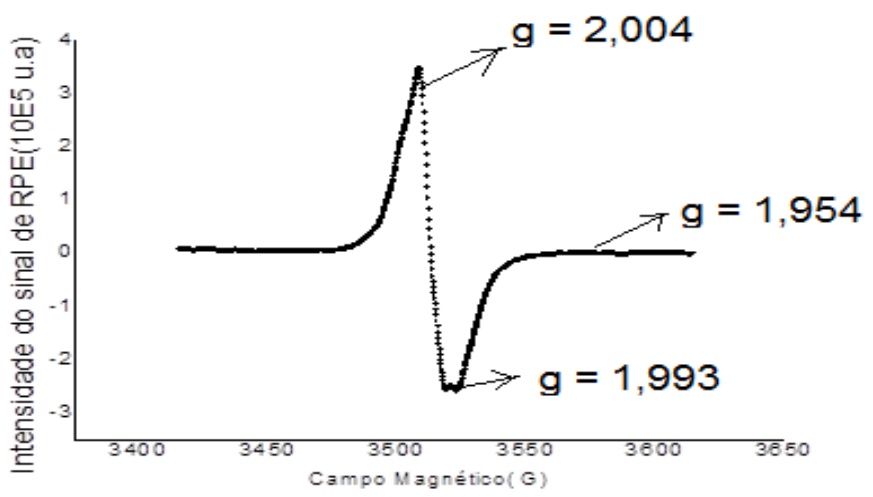

b)

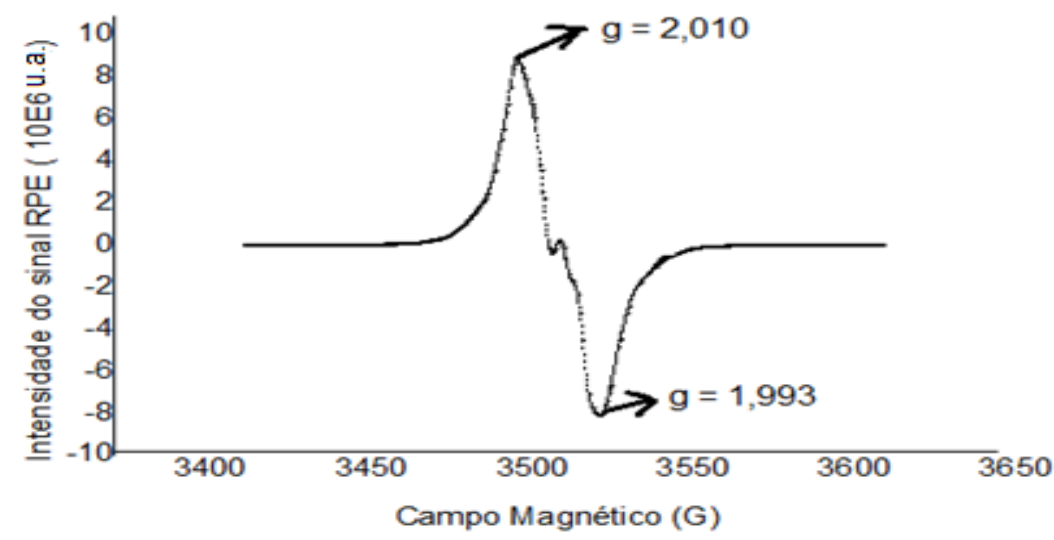

FIGURA 13 - Comparação dos sinais de EPR de amostras de amido de milho irradiadas com dose de 10 (a) e 20 kGy (b) , 1 dia após a irradiação . 
a)

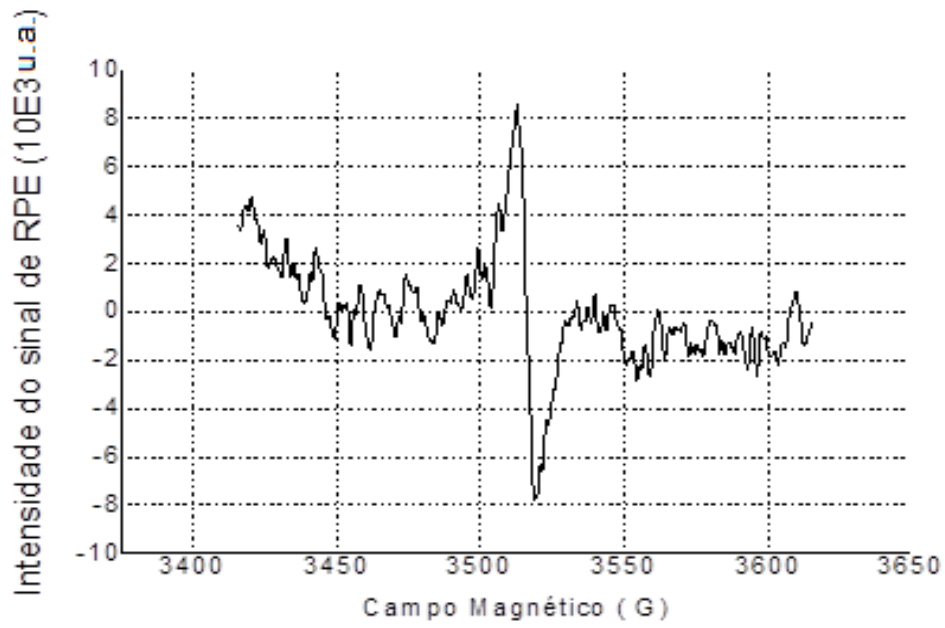

b)

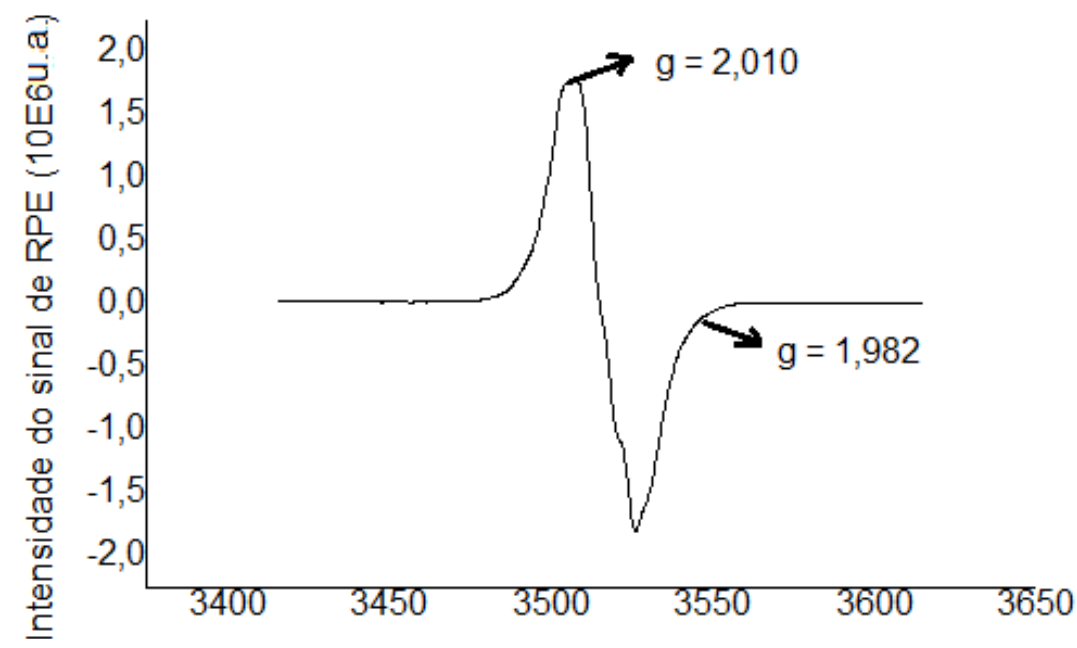

c

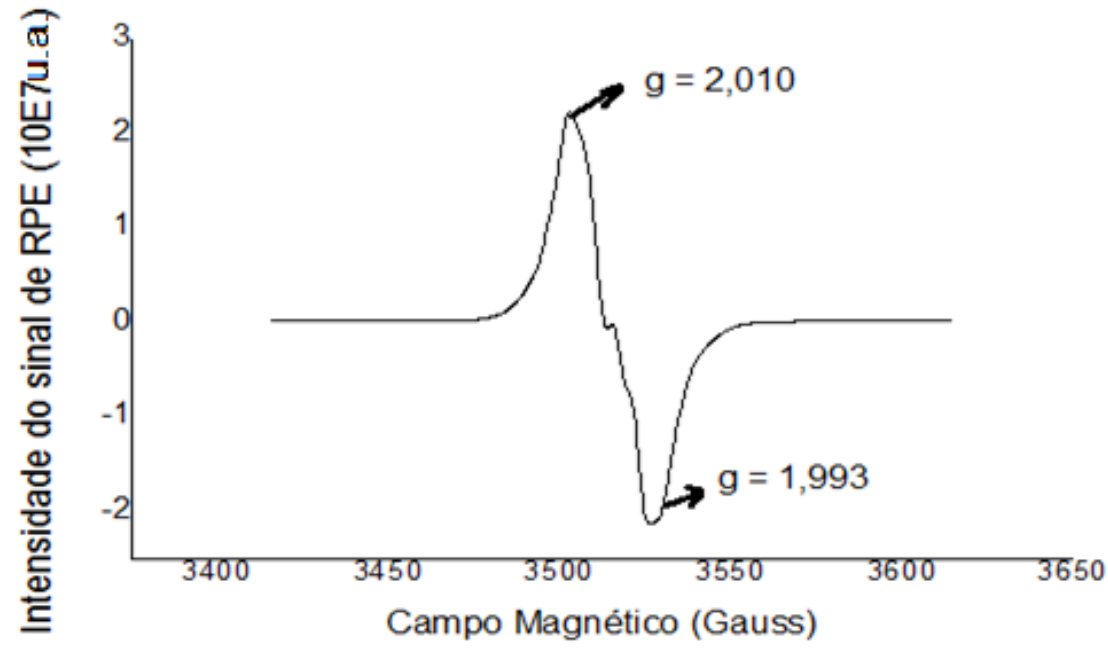

FIGURA 14 - Comparação dos sinais de EPR de amostras de amido de batata irradiadas com dose de 0 (a), 10 (b) e 20kGy (c). 
a)

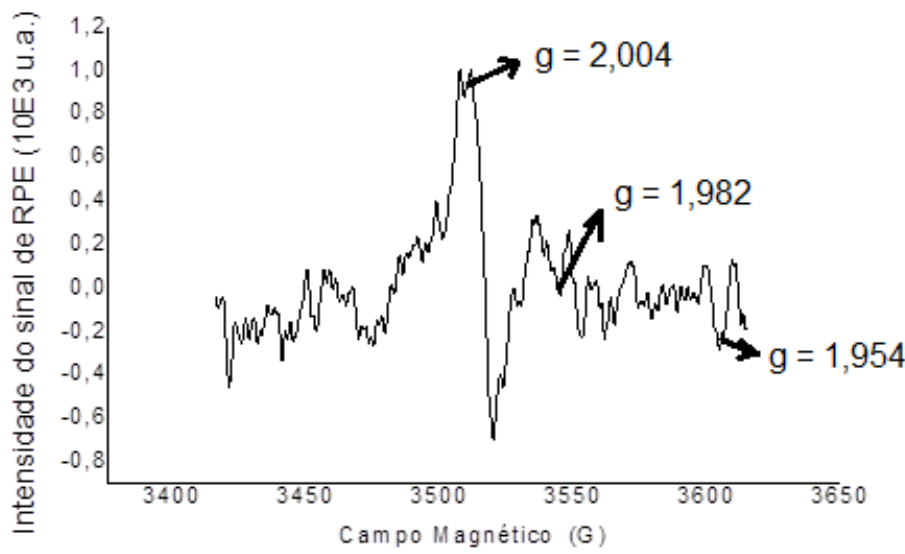

b)

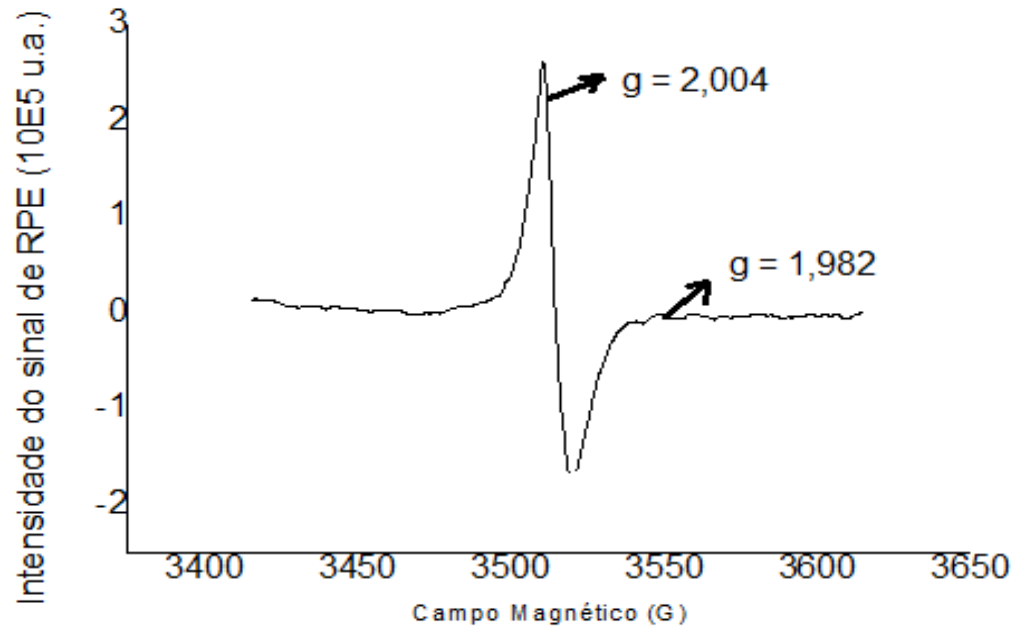

c)

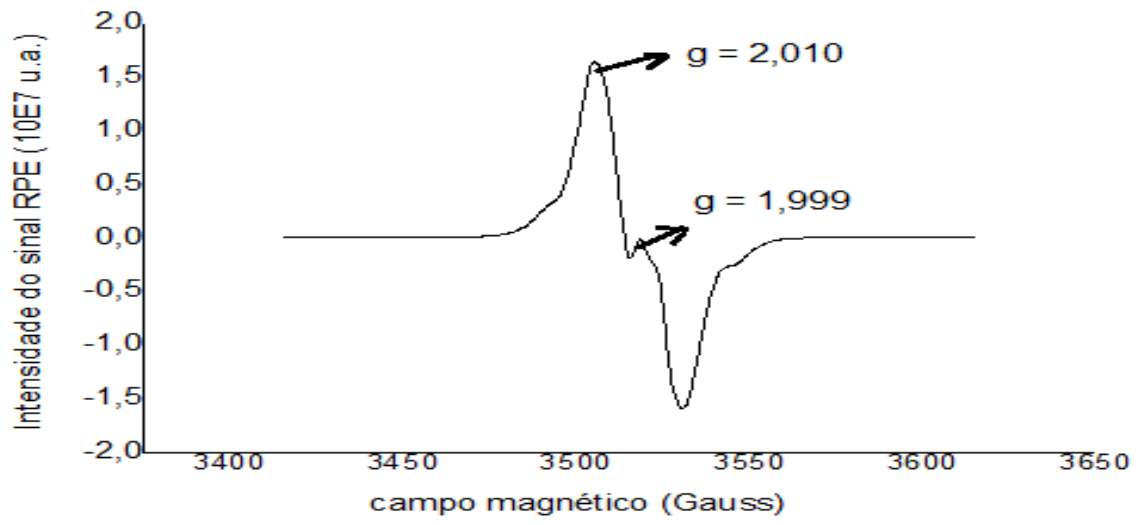

FIGURA 15 - Comparação dos sinais de EPR de amostras de polvilho azedo irradiadas com dose de $0(a), 10(b)$ e $20 \mathrm{kGy}(c), 1$ dia após irradiação. 
Fazendo a comparação da intensidade do sinal nas amostras de amido de milho, batata e polvilho (FIG 13, 14 e 15) irradiadas com dose de 0, 10 e 20 kGy, observa-se que a aplicação de doses maiores, provoca um sinal mais intenso. Como o sinal é atribuído à presença de radicais livres, a diferença de intensidade do sinal está vinculada às diferenças intrínsecas de cada amido. $\mathrm{A}$ presença de sinal de radicais livres em amostras não irradiadas pode ser atribuída a que os amidos não são substâncias puras, contém um mínimo de $80 \%$ de amido. $O$ amido de milho comercial pode conter menos restos de outros produtos vegetais, além de amido, responsáveis pelo sinal mesmo quando não irradiado.

Nas FIG 16, 17 e 18 são apresentados os espectros de RPE de amostras de amido de milho, batata e polvilho azedo respectivamente, irradiadas com doses de $30 \mathrm{kGy}$, mas utilizando para efetuar as medições quantidades inferiores de amostras que nos experimentos anteriores e diferentes condições experimentais. O sinal de RPE resultou menor do que anteriormente, sendo o tempo de mediação, cerca de 5 horas após a irradiação.

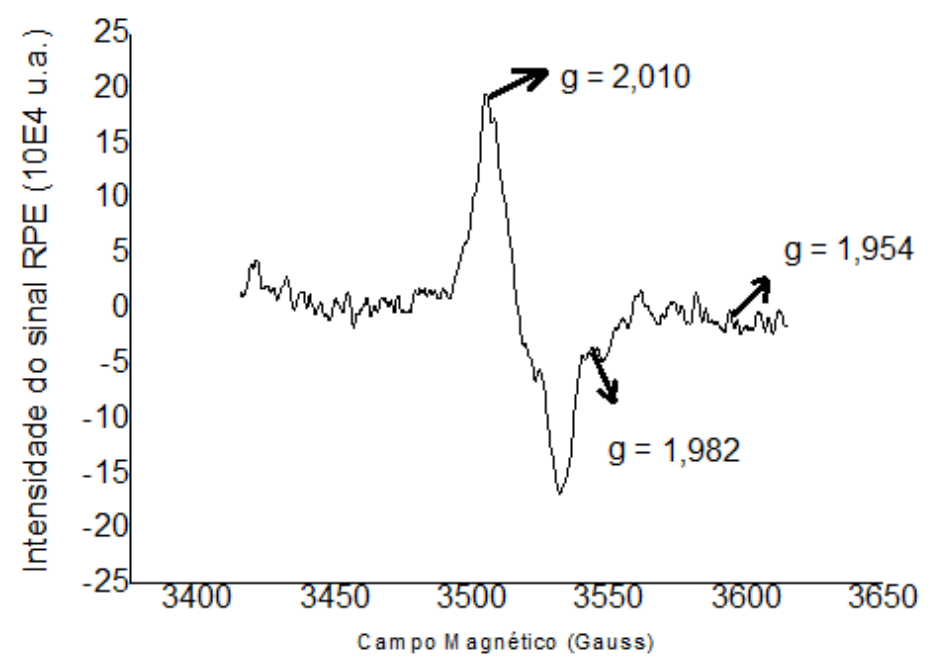

FIGURA 16 - Sinal de EPR da amostra de amido de milho irradiada com dose de 30kGy. 


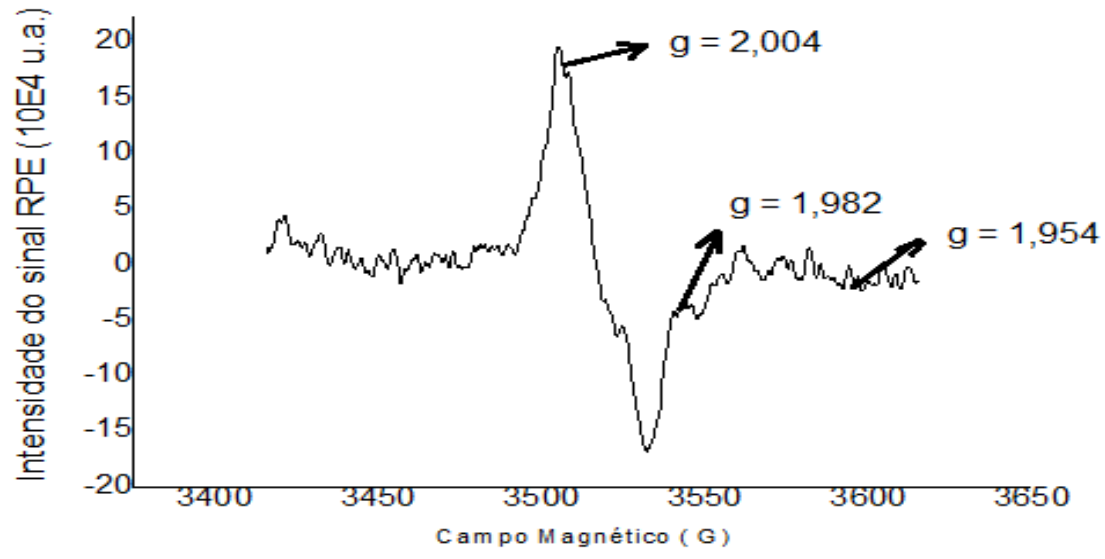

FIGURA 17 - Sinal de EPR da amostra de amido de batata irradiada com dose de 30kGy.

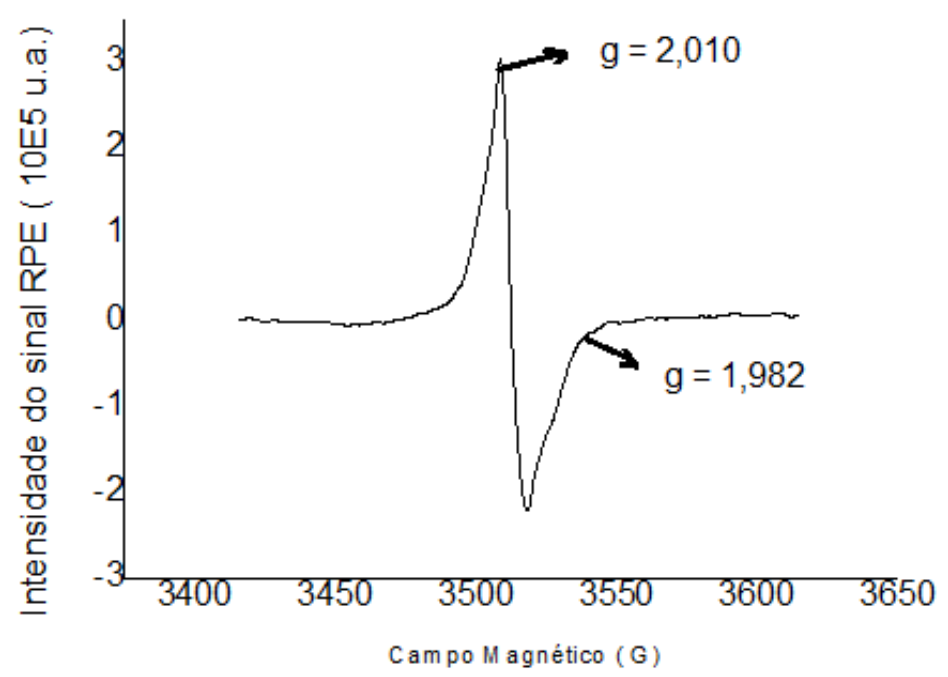

FIGURA 18 - Sinal de EPR da amostra de polvilho azedo irradiado com dose de 30kGy.

Cabe salientar, que não houve determinação específica do teor de umidade das amostras. Também, conteúdo de amilose, que é menor para amido de milho do que para batata e mandioca fermentada ou polvilho azedo (TAB 1), poderia ter influência na geração de radicais livres e ou no sinal de EPR. 


\subsection{Decaimento do sinal de RPE em amidos irradiados}

Nas FIG 19, 20 e 21 são apresentados os decaimentos do sinal de RPE de amido de milho, batata e polvilho azedo irradiados com dose de 10kGy, seguidos durante um período de $1000 \mathrm{~h}$ após irradiação. Os pontos experimentais destas figuras foram ajustados por uma função constituída pela soma de duas exponenciais: $y=y_{0}+A_{1} \cdot \exp ^{\left(\frac{-x}{t 1}\right)}+A_{2} \cdot \exp ^{\left(\frac{-x}{t 2}\right)}$

Esses ajustes levantam a hipótese que o sinal é constituído por mais de um componente. As curvas foram normalizadas para assim facilitar a interpretação da cinética de decaimento de cada amostra.

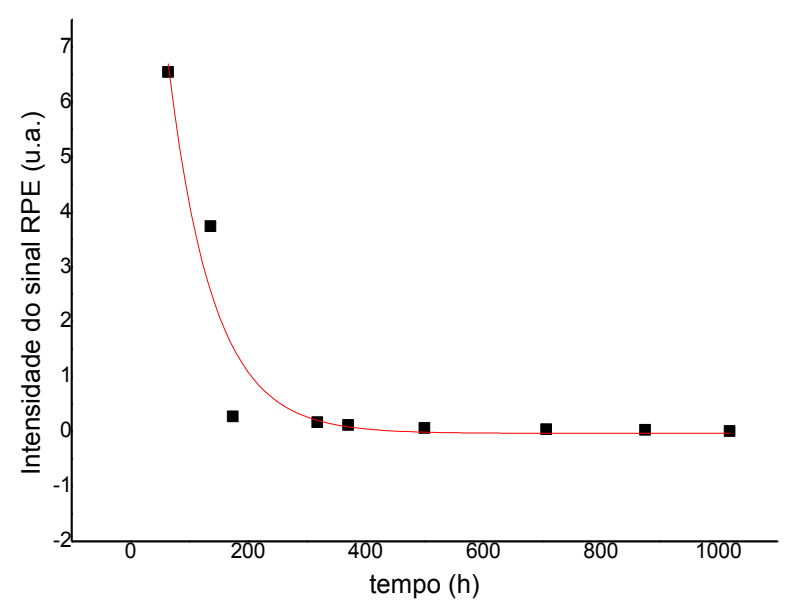

FIGURA 19 - Decaimento do sinal de RPE de amido de milho irradiado com dose de 10 kGy. 


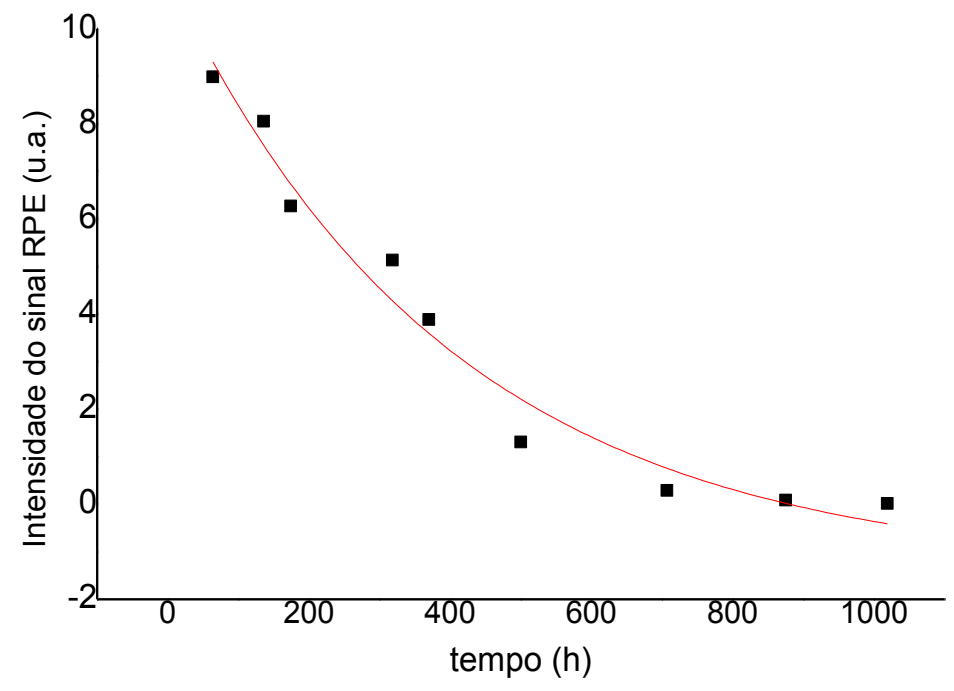

FIGURA 20 - Decaimento do sinal de RPE de amido de batata irradiado com dose de 10 kGy.

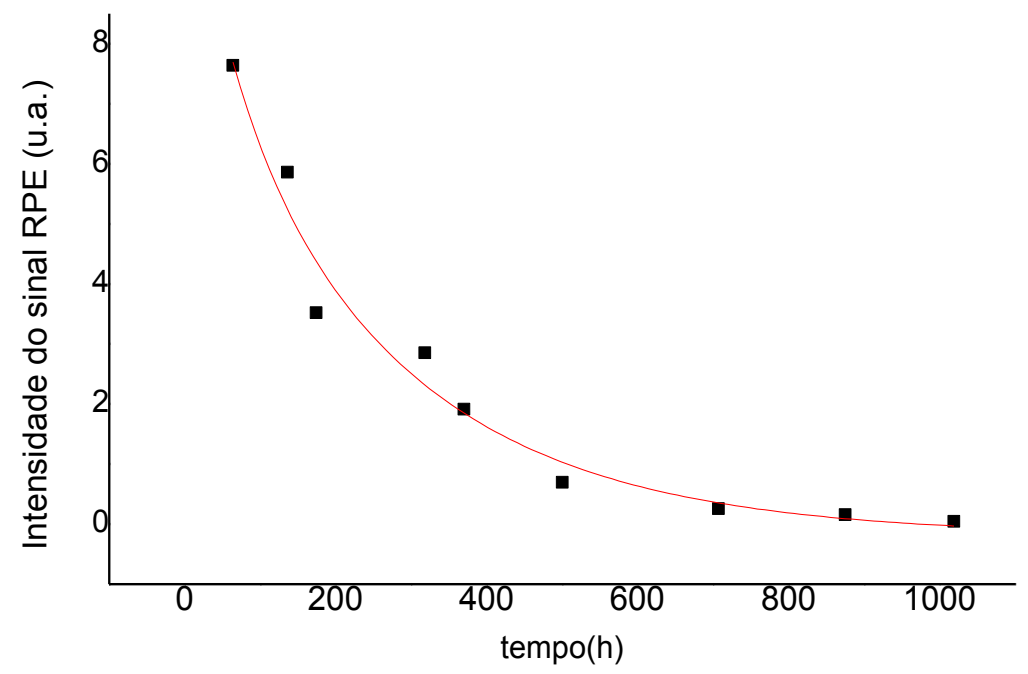

FIGURA 21 - Decaimento do sinal de RPE de polvilho azedo irradiado com dose de 10 kGy.

No decaimento do sinal da amostra de milho, batata e polvilho irradiadas com dose de $10 \mathrm{kGy}$, verifica-se que o sinal diminui com tempo tornando-se insignificante após 400 horas (16 dias), na amostra de amido de milho (FIG 19), amostra de amido de batata (FIG 20), depois de 1000 horas. Ocorrendo o mesmo comportamento na amostra de polvilho azedo (FIG 21). Cattani (1995) 
já tinha reparado que em amostras estocadas a temperatura ambiente e com teor de umidade de 14\%, o sinal de RPE induzido por irradiação com 1 kGy, era possível ser detectado por no máximo 5 dias.

Nas FIG 22, 23 e 24 são apresentados os decaimentos do sinal de RPE de amido de milho, batata e polvilho azedo irradiados com dose de 20kGy, seguidos por $350 \mathrm{~h}$.

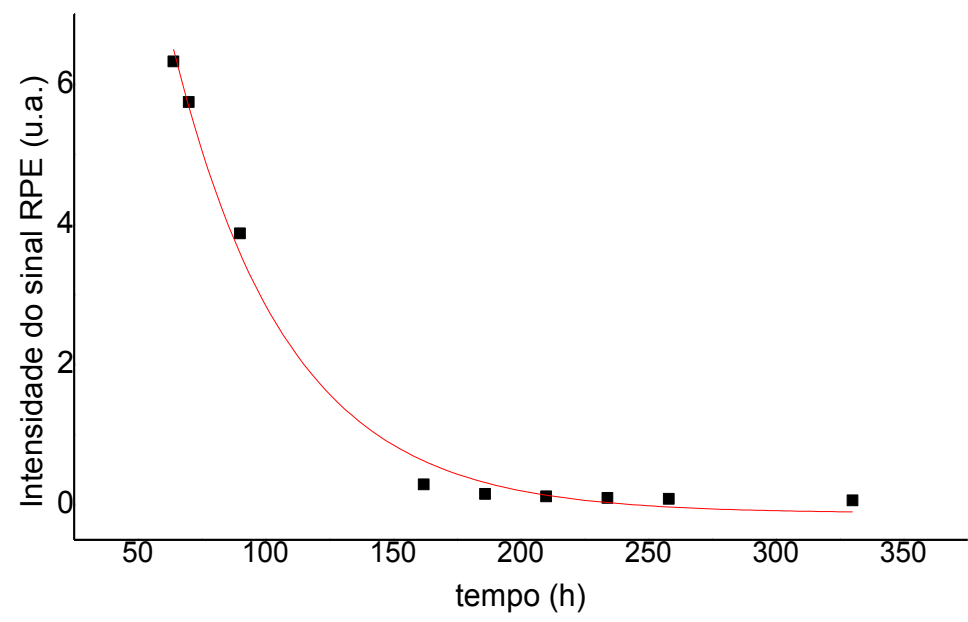

FIGURA 22 - Decaimento do sinal de RPE de amido de milho irradiado com dose de 20 kGy.

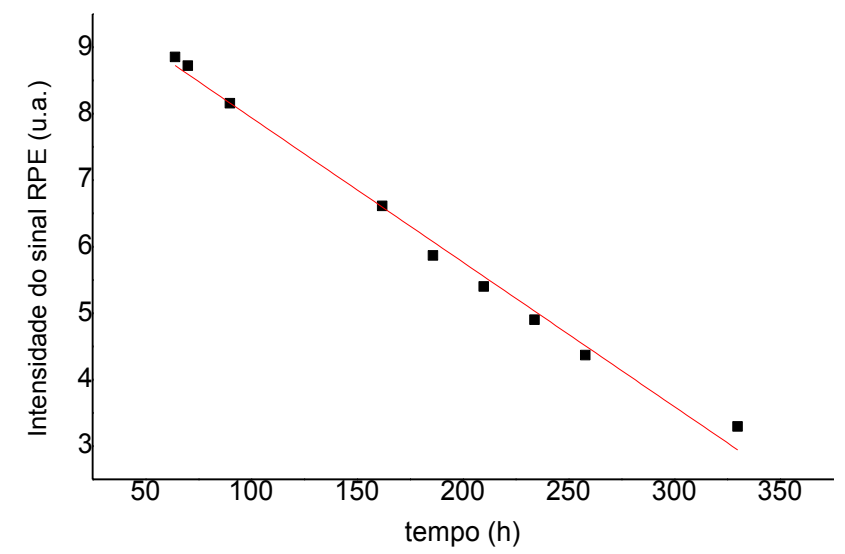

FIGURA 23 - Decaimento do sinal de RPE de amido de batata irradiado com dose de 20 kGy. 


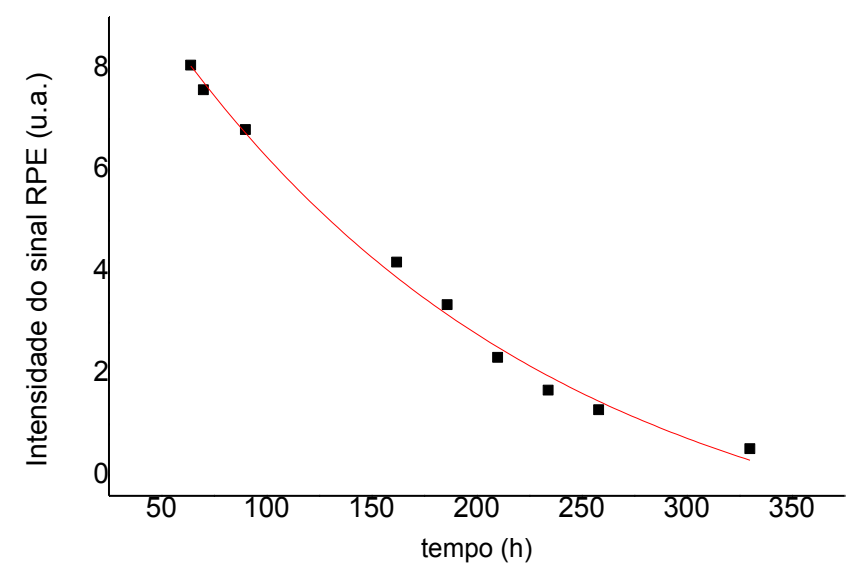

FIGURA 24 - Decaimento do sinal de RPE de polvilho azedo irradiado com dose de 20 kGy.

No decaimento do sinal da amostra de milho, batata e polvilho irradiadas com dose de $20 \mathrm{kGy}$, verifica-se que o sinal diminui com tempo de maneira exponencial tornando-se constante após 200 horas, na amostra de milho (FIG 22). Na amostra de amido de batata irradiada com 20 kGy (FIG 23), foi possível ajustar o decaimento do sinal de RPE para a equação de uma reta excepcionalmente. Na amostra de polvilho (FIG 24), o sinal vai diminuindo de maneira exponencial.

Nas amostras de amidos irradiados com doses de 30 kGy (FIG 25, 26 e 27) o decaimento do sinal foi acompanhado por um período de $350 \mathrm{~h}$. Mas já a partir de $100 \mathrm{~h}$ praticamente não foi detectado sinal de RPE, ou seja, presença de radicais livres. 


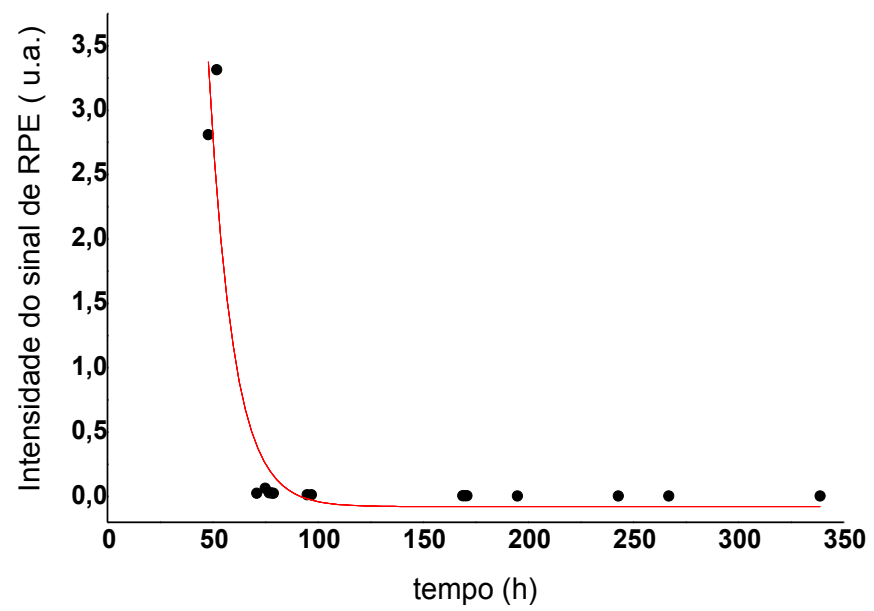

FIGURA 25 - Curva de decaimento do sinal de RPE de amido de milho irradiada com dose de 30 kGy.

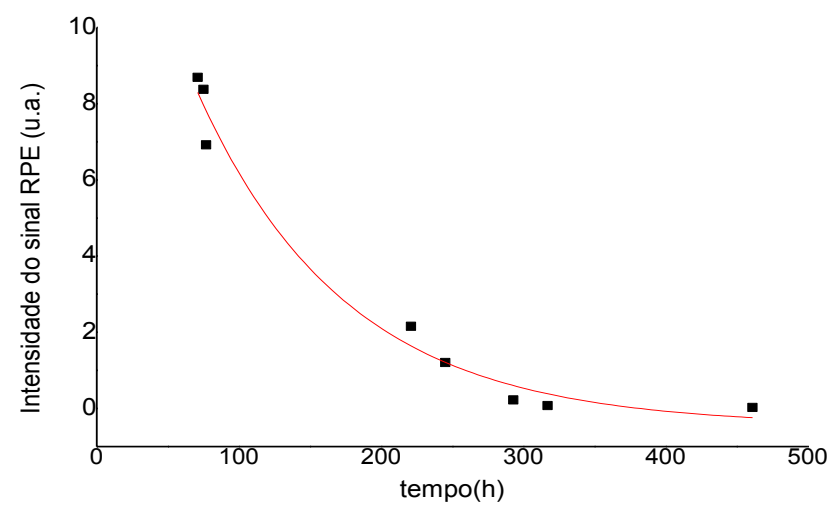

FIGURA 26 - Curva de decaimento do sinal de RPE de amido de batata irradiada com dose de 30 kGy.

Nota-se que o decaimento é bem acentuado nas primeiras 100 horas após da irradiação, o que mostra que os radicais gerados na irradiação foram interagindo rapidamente. 


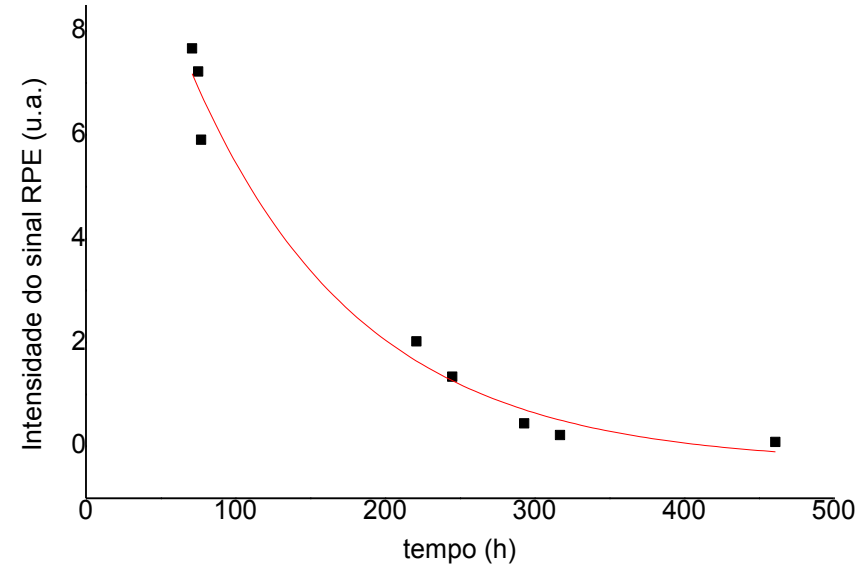

FIGURA 27 - Curva de decaimento do sinal de RPE de polvilho azedo irradiado com dose de 30 kGy.

No decaimento do sinal de RPE de milho, batata e polvilho irradiados, verifica-se que o decaimento é semelhante nas amostras de milho (FIG 19, 22 e 25) e polvilho (FIG 21, 24 e 27). Mas na amostra de amido de batata, irradiado com 20 kGy (FIG 23), o decaimento segue uma função linear e não exponencial.

Nas TAB 2, 3 e 4 estão os dados das equações e ajustes das curvas de decaimento de cada amido para as doses ensaiadas. 
TABELA 3 - Parâmetros da curva de decaimento de sinal de RPE de amido de milho

\begin{tabular}{|c|c|c|c|c|c|c|c|}
\hline $\begin{array}{l}\text { Dose } \\
\text { kGy }\end{array}$ & Equação & ajuste & yo & A1 & t1 & t2 & A2 \\
\hline 10 & $y=A 1^{*} \exp (-x / t 1)+A 2^{*} \exp (-x / t 2)+y 0$ & 0,8615 & $-0,003$ & 0,784 & 75,647 & 75,643 & 0,784 \\
\hline 20 & $Y=A 1^{*} \exp (-x / t 1)+A 2^{*} \exp (-x / t 2)+y 0$ & 0,9894 & $-0,0118$ & 1,3781 & 44,86 & 44,86 & 1,3781 \\
\hline 30 & $y=A 1^{*} \exp (-x / t 1)+A 2^{*} \exp (-x / t 2)+y 0$ & 0,5625 & 0,0011 & 0,1110 & 23,56 & 23,56 & 0,1110 \\
\hline
\end{tabular}

TABELA 4 - Parâmetros da curva de decaimento de sinal de RPE de amido de batata

\begin{tabular}{|c|c|c|c|c|c|c|c|}
\hline Dose kG & Equação & ajuste & yo & A1 & t1 & t2 & A2 \\
\hline 10 & $y=A 1^{*} \exp (-x / t 1)+A 2^{*} \exp (-x / t 2)+y 0$ & 0,8615 & $-0,14015$ & 0,6077 & 401,30 & 401,28 & 0,784 \\
\hline 20 & $Y=a+b x$ & 0,9907 & $a=-0,002$ & $\mathrm{~b}=1,011$ & & & $\begin{array}{l}---- \\
---- \\
---\end{array}$ \\
\hline 30 & $y=A 1^{*} \exp (-x / t 1)+A 2^{*} \exp (-x / t 2)+y 0$ & 0,9620 & $-0,0452$ & 0,8609 & 104,87 & 104,87 & 0.8609 \\
\hline
\end{tabular}


TABELA 5 - Parâmetros da curva de decaimento de sinal de RPE de polvilho azedo

\begin{tabular}{|c|c|c|c|c|c|c|c|}
\hline $\begin{array}{l}\text { Dose } \\
\text { kGy }\end{array}$ & Equação & ajuste & yo & A1 & t1 & t2 & A2 \\
\hline 10 & $y=A 1^{*} \exp (-x / t 1)+A 2^{*} \exp (-x / t 2)+y 0$ & 0,9478 & 0,0190 & 0,3240 & 62,0013 & 255,43 & 0,8643 \\
\hline 20 & $y=A 1^{*} \exp (-x / t 1)+A 2^{*} \exp (-x / t 2)+y 0$ & 0,9892 & $-0,2190$ & ), 7183 & 188,30 & 188,30 & 0,7183 \\
\hline 30 & $y=A 1^{*} \exp (-x / t 1)+A 2^{*} \exp (-x / t 2)+y 0$ & 0,9546 & $-0,00340$ & 0,7057 & 112,642 & 112,642 & 0,7057 \\
\hline
\end{tabular}

O decaimento do sinal de RPE é um indicativo da cinética do desaparecimento dos radicais livres presentes nas amostras com o passar do tempo. Observa-se que para uma mesma dose de radiação, as diversas amostras apresentam diferentes valores dos parâmetros e de ajustes de cada equação.

Bidzinska et al. (2015) estudaram radicais estáveis e de curta duração gerados termicamente em amidos de várias origens botânicas. Esses radicais foram utilizados como indicadores de mudanças nas estrutura do amido. Segundo esses autores, o amido aquecido a $300^{\circ} \mathrm{C}$ revelou propriedades protetoras contra radiação ionizante. Utilizando o RPE, eles demostrou que os radicais termicamente gerados de curta duração podem ser usados como sondas sensíveis a mudança de estruturas em amidos nativos.

No presente trabalho pode-se apontar que as amostras terem tempo de decaimentos diversos. A forma de armazenamento, as condições de produção dos amidos, o aquecimento desordenado, a presença de outras substâncias, pode gerar regiões de instabilidade, alterando o equilíbrio entre regiões amorfas e cristalinas dos grânulos de amido, que pode afetar na medição do sinal e também no decaimento do sinal.

Como mostram as equações nas amostras de amido de milho, batata e mandioca (polvilho azedo) (TAB 2 e 3 ) as curvas de decaimento tem 2 
componentes exponenciais; A1 e A2 são as amplitudes do sinal e y0 é o deslocamento da onda de sinal.

A ingónita $x$ se refere a taxa de decaimento do sinal ao longo do tempo, sendo que se dividirmos por In2 encontraremos o tempo médio de decaimento do sinal de cada amostra.

Já na amostra de amido de batata irradiada com 20 kGy, observa-se que a decaimento foi excepcionalmente linear conforme já mencionado, seguindo a equação $y=a+b^{*} x$. Na amostra de polvilho se manteve o comportamento exponencial e com semelhanças nos valores dos parâmetros (TAB 4).

\subsubsection{Espectroscopia FTIR}

Como foi mencionado, a absorção na região do infravermelho é causada por movimentos rotacionais e vibracionais dos grupos moleculares e ligações químicas de uma molécula, provocando o aumento da amplitude das vibrações moleculares (LOPES \& FACIO, 2004). No presente estudo, foi analisado o efeito da irradiação ionizante nos espectros de absorção no IV de amido de milho, de batata e de mandioca fermentada (polvilho azedo).

Nas análises de absorção no infravermelho deve ser levado em consideração que nas regiões de 1550 a $4000 \mathrm{~cm}^{-1}$ são encontradas as vibrações de estiramento; de 950 a $1550 \mathrm{~cm}^{-1}$ as vibrações de estiramento e deformação; de 400 a $950 \mathrm{~cm}^{-1}$ as vibrações fora do plano. As modificações possíveis no caso de espectros de amidos podem ser encontradas nas duas primeiras regiões mencionadas.

Amidos de milho, batata e mandioca fermentada (polvilho azedo) tratados com doses de 0, 10 e 20 kGy de radiação gama foram analisados por Espectroscopia no infravermelho com transformada de Fourier (FTIR). Nas FIG 28, 29 e 30 são apresentados os resultados da espectroscopia no infravermelho por transformada de Fourier (FITR) das amostras irradiadas com dose de 0, $10 \mathrm{e}$ 20 kGy.

Nas análises de absorção no infravermelho deve ser levado em consideração que nas regiões de 1550 a $4000 \mathrm{~cm}^{-1}$ são encontradas as 
vibrações de estiramento; de 950 a $1550 \mathrm{~cm}^{-1}$ as vibrações de estiramento e deformação; de 400 a $950 \mathrm{~cm}^{-1}$ as vibrações fora do plano. As modificações possíveis no caso de espectros de amidos podem ser encontradas nas duas primeiras regiões mencionadas.

Os espectros de amidos de milho, batata e polvilho azedo apresentam grande semelhança entre si (FIG 28, 29 e 30). A pesar de que os espectros não foram modificados pela radiação, houve aumento das intensidades de absorbância encontradas a $1000 \mathrm{~cm}^{-1}$ atribuídas a vibrações de estiramento e deformação de C-O-H e que já fora correlacionado com o estado amorfo do amido (BASHIR \& AGGARWAL, 2016). Também, na banda extremamente ampla ao redor de $3287 \mathrm{~cm}^{-1}$ atribuida ao estiramento do hidrogênio ligado $\mathrm{O}-\mathrm{H}$, na banda a $2905 \mathrm{~cm}^{-1}$ atribuida a vibrações de estiramento de $\mathrm{C}-\mathrm{H}$, na banda a $1656 \mathrm{~cm}^{-1}$, vibrações de estiramento de $\mathrm{H}-\mathrm{O}-\mathrm{H}$ e na banda a $1385 \mathrm{~cm}^{-1}$, atribuida a vibrações rotacionais de O-C-H, C-C-H e C-O-H. Bashir, Jan e Aggarwal (2017) também obtiveram resultados semelhantes trabalhando com farinha de trigo irradiada com dose de $10 \mathrm{kGy}$. Bhat et al.(2016) trabalhando com diferentes cultivares de trigo, irradiados com até $5 \mathrm{kGy}$, encontraram que a intensidade de absorção no IV de grupos funcionais decrescia ou aumentava com o aumento da dose, dependendo do cultivar.

Lima, et al. (2012) consideram as bandas na região 1200 a $1000 \mathrm{~cm}^{-1}$ como bandas características do amido atribuídas a vibrações de deformação de axial de $\mathrm{C}-\mathrm{O}$ e C-O-C .

De acordo com Silverstein et al. (1991), o espectro de infravermelho do amido nativo apresenta bandas na região de $2900-3000 \mathrm{~cm}^{-1}$, correspondente estiramento $\mathrm{C}-\mathrm{H}$, em 1163, 1150, 1124 e $1103 \mathrm{~cm}^{-1}$ que correspondem ao estiramento $\mathrm{C}-\mathrm{O}$ e $\mathrm{C}-\mathrm{C}$ com alguma contribuição do estiramento $\mathrm{C}-\mathrm{OH}$. As bandas em 1077, 1067, 1022,994 e $928 \mathrm{~cm}^{-1}$ são atribuídas as deformações $\mathrm{C}-\mathrm{OH}$ e $\mathrm{CH}_{2}$. O grupo C-O-C ( éter) presente em um anel de seis átomos (como no monômero de glicose) absorve em $1150-1085 \mathrm{~cm}^{-1} \mathrm{e}$ dependendo de deformação axial ( simétrica ou assimétrica) essas bandas irão se deslocar. 


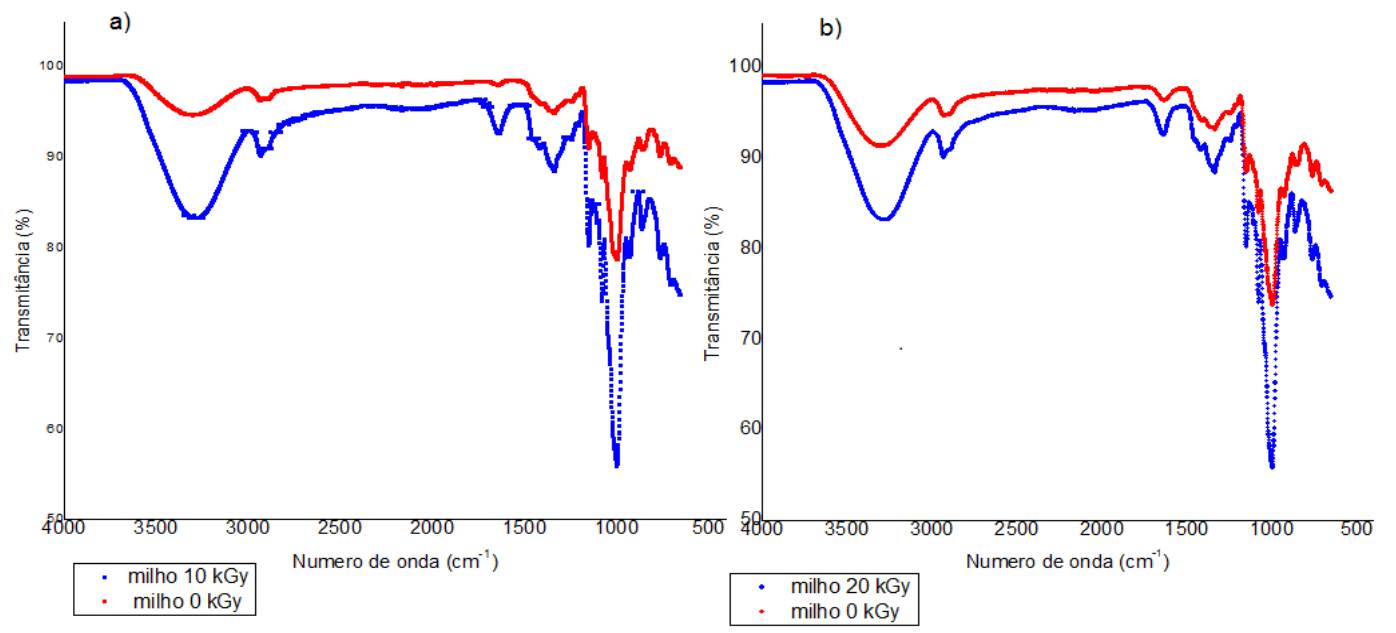

FIG 28 - Espectro FTIR de amido de milho irradiado com dose de 0 e 10 kGy (a) e 0 e 20 kGy (b).

No espectro da amostra de milho irradiada com dose de $10 \mathrm{kGy}(\mathrm{a})$ observa-se um incremento na absorção na banda de $2900-2750 \mathrm{~cm}^{-1}$ e na banda 1750$1600 \mathrm{~cm}^{-1}$. Isso é referente a vibração de estiramento dos átomos de carbono e hidrogênio, conforme tabela 6 . No caso da amostra irradiada com dose de 20 kGy(a) ocorrem absorções referentes a própria estrutura molecular do amido.

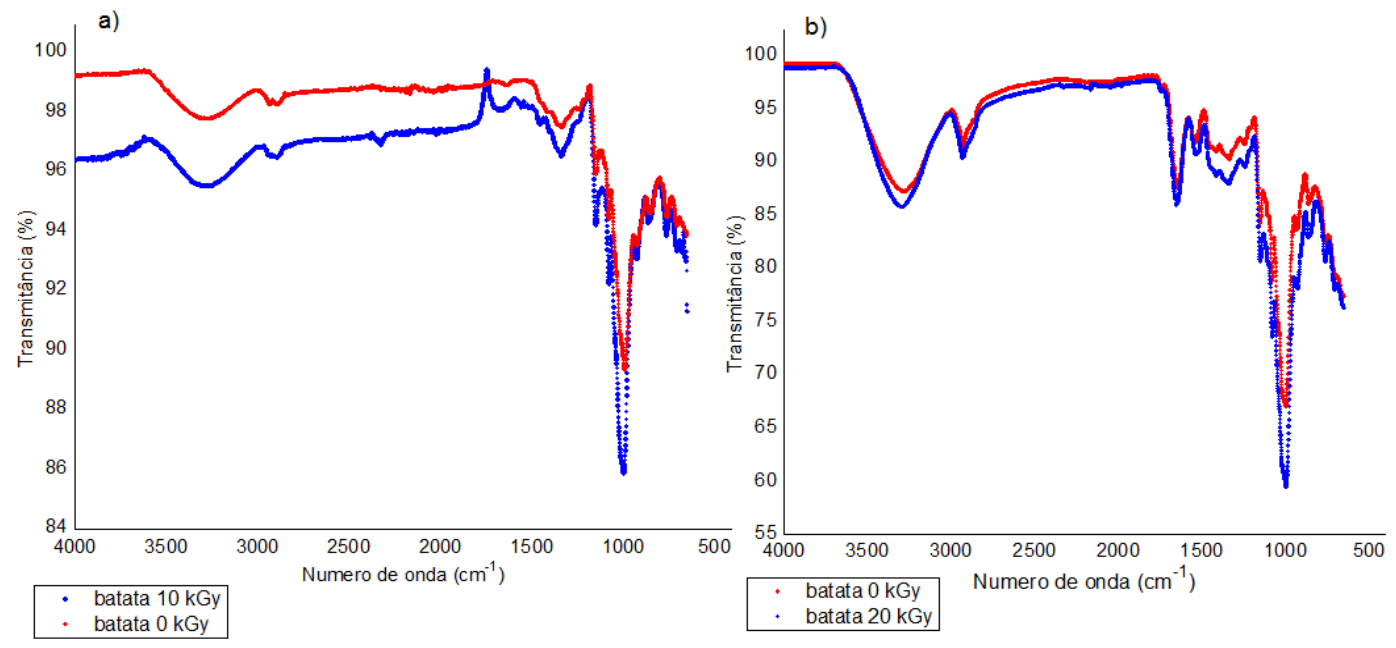

FIG 29 - Espectros FTIR de fécula de batata irradiada com doses de 0 e 10 kGy (a) e 0 e 20 kGy (b). 
No espectro da amostra de batata irradiada com dose de $10 \mathrm{kGy}(\mathrm{a})$ observa-se uma absorção na banda de 1800-1650 $\mathrm{cm}^{-1}$. Isso é referente a vibração de estiramento dos átomos de carbono e oxigênio, conforme tabela 7 . No caso da amostra irradiada com dose de 20 kGy(a) ocorrem absorções referentes a própria estrutura molecular do amido.
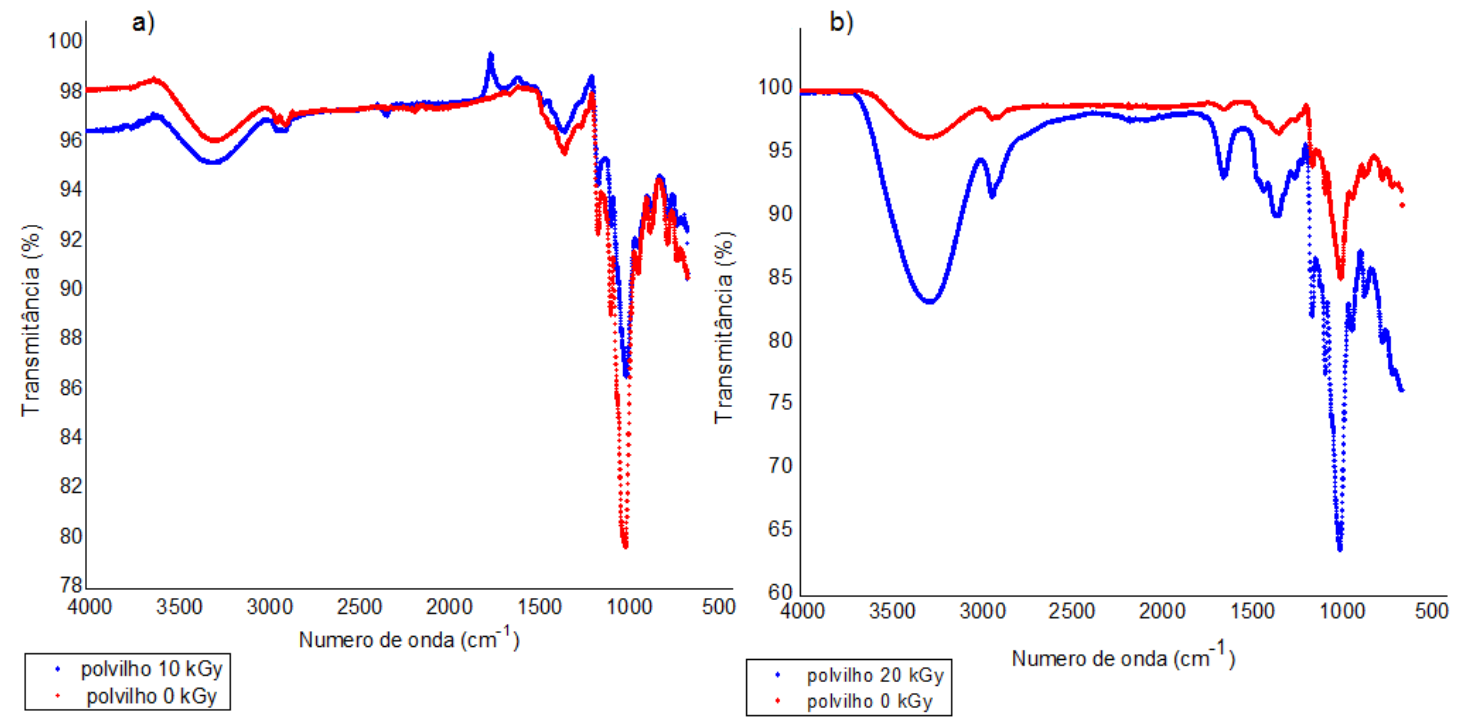

FIG 30 - Espectros FTIR de polvilho azedo irradiado com dose de 0 e 10 kGy (a) e 0 e 20 kGy (b)

No espectro da amostra de polvilho irradiada com dose de $10 \mathrm{kGy}(\mathrm{a})$ observa-se uma absorção na banda de 1850-1700 $\mathrm{cm}^{-1}$. Isso é referente a vibração de estiramento dos átomos de carbono e oxigênio,sendo que existe uma dupla ligação com o átomo de oxigênio favorecendo a maior absorção. No caso da amostra irradiada com dose de 20 kGy(a) ocorrem absorções referentes a própria estrutura molecular do amido.

Assim, houve para os 3 amidos ensaiados, pequena intensificação da absorção nas regiões do espectro correspondentes a estiramento e deformação angular das ligações -OH (3400 e $1650 \mathrm{~cm}^{-1}$ ) e deformação axial de ligações C$\mathrm{H}$ (próximo a $2926 \mathrm{~cm}^{-1}$ ). Também, é possível perceber modificações nas bandas características de amido atribuídas a vibrações de deformação axial de C-O e a vibrações de deformação axial do sistema O-C-O (1200- $\left.1000 \mathrm{~cm}^{-1}\right)$. 


\section{CONCLUSÃO}

A partir dos resultados obtidos neste estudo é possível concluir que:

A radiação ionizante proveniente de fonte gama modifica propriedades físicas e químicas de macromoléculas como os amidos de milho, batata e mandioca (polvilho azedo) utilizados neste estudo. A aplicação das técnicas utilizadas no trabalho experimental desta dissertação, RPE e FTIR, forneceu informação sobre alguns aspectos do comportamento de amidos sob a ação da radiação ionizante. A produção de sinal de RPE em amostras de amido de milho, batata e mandioca fermentada (polvilho azedo) estaria associada à presença de radicais livres gerados pela radiação. Entretanto, amidos de batata e polvilho azedo apresentaram pequeno sinal mesmo em amostras não irradiadas, o que poderia ser atribuído à presença de outros componentes vegetais. $A$ intensidade do sinal de RPE aumentou com o aumento da dose aplicada para todos os amidos, mas mostrou ser pouco estável em função do tempo. Os valores obtidos do fator $\mathrm{g}$ foram próximos do valor teórico de 2,0023. O decaimento do sinal de RPE em função do tempo foi de caráter exponencial, exceto na amostra de amido de batata irradiada com dose de $20 \mathrm{kGy}$, que decaiu linearmente com a dose. Para milho e polvilho azedo, o ajuste das curvas de decaimento foi a soma de duas exponenciais, o seja, o sinal é constituído por 2 componentes. Houve modificações nos espectros de infravermelho analisados pela transformada de Fourier nos amidos de milho, batata e polvilho azedo irradiados, mas que não caracterizam mudanças estruturais ou formação de novos grupos.

Este trabalho pode contribuir para pesquisas futuras com irradiação em amidos. Em estudos sobre aplicação da RPE em amidos, fica evidente a necessidade de levar em consideração, não só os processos de geração de radicais livres, mas também as condições que determinam a estabilidade do sinal. 


\section{REFERÊNCIAS BIBLIOGRÁFICAS}

- AlCAZAR-ALAY, S.C. \& MEIRELES, M.A.A. Physicochemical properties, modifications and appplications of starches from different botanical sources. Food Sc. Technol., Campinas, v. 35, n. 2, p. 215-236, 2015.

- ASCHERI, D. P. R.; VILELA, E. R. Alterações do polvilho de mandioca pela fermentação, no fabrico de biscoitos. Pesquisa Agropecuária Brasileira., v.30, n.2, p.269-279, 1995.

- ASP, N.G.; BJÖRCK, I. Resistant Starch. Trends Food Sc.Technol., v. 3, p. 111-114, 1992.

- ATHERTON, N.M. Principles of Electron Spin Resonance. Horwood, Chlchester.

- BASHIR, K,; JAN, K.; AGGARWAL, M. Thermo- Reological an Functional Properties of Gamma - Irradiated Wholewheat Flour. International Journal of Food Sciencie an Tecnology. 2017.

- BASHIR, K.; AGGARWAL, M. Effects of gamma irradiation on the physicochemical, thermal and functional properties of chickpea flour. LWT Food Science and Technology, v. 69, p. 614-622, 2016.

- BASHIR, K.; JAN, K.; AGGARWAL, M. Thermo-rheological and functional properties of gamma-irradiated wholewheat flour. International Journal of Food Science and technology, v. 52, p. 927-935, 2017.

- BHAT, N.A.; WANI, I.A.; HAMDANI, A.M.; GANI, A. Physicochemical properties of whole wheat flour as affected by gamma irradiation. LWT - Food Science and Technology, v. 71, p. 175-183, 2016.

- BHAT, R.; SRIDHAR, K. R. Detection of free radicals in electron beam-irradiated Mucuna pruriens (L. DC.) seeds by electron spin resonance. Food Science and Technology International, v. 13, n. 4, p. 249-257, 2007.

- BIDZIŃSKA, E. Thermally Generated, Radicals as Indicators of The Starch Modification Studied by EPR Spectroscopy. Faculty of Chemistry Jagtelloniam University Ingardena. 2015 
- BIDZIŃSKA, E.; DYREK, K.; WENDA, E. Electron paramagnetic resonance study of thermally generated radicals in native and modified starches. Current Topics in Biophysics, v. 33, suppl A, p. 21-25, 2010.

- BRACEWELL, R.N. "The Fourier Transform Spectroscopy", Academic Press, N. Y., 1972.

- BRAGA, M. E. M.; MORESCHI, S. R. M.; MEIRELES, A. A. Effects of supercritical fluid extraction on Curcuma longa $L$. and Zingiber officinale $R$. starches. Carbohydrate Polymers, Barking, v. 63, n. 3, p. 340 - 346, 2006.

- BRASIL. Ministério Da Saúde. Resolução - RDC n. 21 de Janeiro de 2001. Agência Nacional de Vigilância Sanitária. República Federativa do Brasil Diário Oficial Brasília. DF 29 de Janeiro de 2001. N. 20.

- CAMPBELL, J. P.; RYAN, J.T.; SHRESTHA, P. R.; LIU, Z. ; VAZ, C. ; KIM, J.; GEORGIOU, V. ; CHEUNG, K. P. Electron spin resonance scanning probe for ultrasensitive biochemical studies. Analytical Chemistry, v. 87, n. 9, p. 49104916, 2015.

- CARRINGTON, A.; McLACHLAN, A.D. Introduction to Magnetic Resonance with applications to chemistry and chemical physics. 1 ed. Tokyo, Harper \& Row, 1967. Cap 1, p. 1 - 12: Principles of Magnetic Resonance.

- CATTANI, M.M. Estudo por Ressonância Paramagnética Eletrônica (RPE) em grãos $r$ farináceos irradiados com 60Co. Dissertação de mestrado. IPENUSP, 1995.

- CEREDA, M.P. Avaliação da qualidade de duas amostras de fécula fermentada de man.dioca (polvilho azedo). I. Formulação e preparo de biscoitos. Boletim da Sociedade Brasileira de Ciências de Alimentos. Campinas, v.17, n.3, p.287295. 1983b.

- CEREDA, M.P. Padronização para ensaios de qualidade da fécula fermentada de mandioca ( polvilho azedo). Boletim da Sociedade Brasileira de Ciências de Alimentos. Campinas, v.17, n.3, p.305-320. 1983a.

- CEREDA, M.P.; NUNES, O. G.; VILPOUX, O. Tecnologia da produção de polvilho azedo. Botucatu. Centro de Raízes Tropicais (CERAT). Universidade Estadual Paulista, 1995. 
- CIACCO, C. F.; CRUZ, R. Fabricação de amido e sua utilização. São Paulo: Secretaria de Indústria e Comércio, Ciência e Tecnologia, n. 7, 152p. (Série Tecnologia Agroindustrial), 1982.

- CODEX AlIMENTARIUS COMMISSION. Codex General Standard For Irradiated Foods. CODEX STAN 106-1983, Rev. 1-2003.

- COMMONER, B.; TOWNSEND, J.; PAKE, G.E. Free radicals in Biological Materials. Nature, v. 174, n. 4432, p. 689-691, 1954.

- DELINCEE, H. Analytical methods to identify irradiated food-a review. Radiation Physics and Chemistry, v. 63, n. 3-6, p. 455-458, 2002.

- DUARTE, C L.; VILLAVICENCIO, A. L. C.H.; MASTRO, N.L.; WIENDL, F.M. Detection of irradiated chicken by ESR spectroscopy of bone. Radiation Physics and Chemistry., v. 46, n. 4-6, p. 689-692.

- DYREK, K., MADEJ, A., MAZUR, E. \& ROKOSZ, A. Standards for EPR measurements of spin concentration. Colloids Surf., v. 45, p. 135-144, 1990.

- ELIASSON, A.C. Starch in Food: Structure, Function and Applications, CRCWoodhead Publishing Limited, 624p.

- EN Protocol EN 13708, 2001. Detection of irradiated food containing crystalline sugar: analysis by EPR. European Committee for Standardization, Brussels.

- EN Protocol EN 1786, 1997. Detection of irradiated food containing bone: analysis by electron paramagnetic resonance. European Committee for Standardization, Brussels.

- EN Protocol EN 1787, 2000. Determination of irradiated food containing cellulose: analysis by EPR. European Committee for Standardization, Brussels.

- FANG, G.; LIU, C.; WANG, Y.; DIONYSIOS, D.D.; ZHOU, D. Photogeneration of reactive oxygen species from biochar suspension for diethyl phthalate degradation. Applied Catalysis B: Environmental, v. 214, p. 34-45, 2017.

- FAO. Food and Agriculture Organization. FAOSTAT. Database. Rome, 1999. Disponível em: htpp://faostat,fao.org. Acesso em: 15 março 2016. 
- FASOLIN L., H; ALMEIDA, G.C; CASTANHO, P.S; OLIVEIRA, E.R.N. Biscoitos produzidos com farinha de banana: avaliações química, física e sensorial. Ciênc. Tecnol. Aliment., v. 27 n. 3, p. 524-529, 2007.

- GIUGgioli, N.R.; GIRGENTI, V.; PEANO, C. Qualitative Performance and Consumer Acceptability of Starch Films for the Blueberry Modified Atmosphere Packaging Storage. Pol. J. Food Nutr. Sci., v. 67, n. 2, p. 129-136, 2017.

- GLIDEWELL, S.M.; DEIGHTON, N.; GOODMAN, B.A.; HILLMAN, J.A. Detection of irradiated foods: A review. J. Sci. Food Agric., v. 61, p. 281-300, 1993.

- GOMEZ, J. A.; KINOSHITA, A.; CHEN. E.J.; GUIDELLI, E.J.; RECH, A.B.; ALVES, G.; BAFFA, O. Dosimetria por ressonância magnética electronica. Electron magnetic resonance dosimetry. Revista Brasileira de Física, v. 5, p. 221-232, 2011.

HAN, F.; BAHAIN, J. J.; DENG, C.; BOËDA, É.; HOU, Y. ; WEI, G.; HUANG, W. ; GARCIA, T.; SHAO, Q.; HE, C.; FALGUÈRES, C.; VOINCHET, P.; YIN, G. The earliest evidence of hominid settlement in China: Combined electron spin resonance and uranium series (ESR/U-series) dating of mammalian fossil teeth from Longgupo cave. Quaternary International, v. 434, p.75-84, 2017.

- IAEA - INTERNATIONAL ATOMIC ENERGY AGENCY. Use of Irradiation to Ensure the Higienic quatlity of fresh, pre-cut fruits an vegetables and other minimally processed food of plant origin. Vienna IAEA-TECDOC-1530, December, 2006.

- KAMAL, E., A. FRANK., J. RAZDAN., A. TENGBLAD., S. VESSY., B. Effects of dietary phenolic compounds on tocopherol, cholesterol, and fatty acids in rats. Lipids, v. 35, p. 427-35, 2000.

- LABANOWSKA, L.; KURDIZIEL, M.; FILEK, M.; WALAS, S.; TOBIASZ, A.; WESELUCHA-BIRCZYNSKA, A. The influence of the starch components on thermal radical generation in flours. Carbohydrate Polymers, v. 101, p. 846856, 2014.

- LAJOLO, F. M., MENEZES, E. W. Carbohidratos en alimentos regionales iberoamericanos. 1. ed. São Paulo: EDUSP, 2006. v. 1,648 p. 
- LEAL, A.S.; KRAMBROCK, K.; GUEDES, K.; RODRIGUES, R.R. Ressonância Paramagnética Eletrônica -RPE aplicada à análise de especiarias irradiadas (com radiação gama). Ciênc. Tecnol. Aliment., Campinas, v. 24, n. 3, p. 427430, 2004.

- LIMA, A., BAKKER, J. Espectroscopia no Infravermelho Próximo para monitorização da perfusão tecidual. Departamento de Terapia Intensiva, Erasmus MC Hospital, University Medical Center Rotterdam, Rotterdam, The Netherlands. Artigo de Revisão. 2011.

- LIMA, B.N.B.; CABRAL, T.B.; NETO, R.P.C.; TAVARES, M.I.B. Estudo do Amido de Farinhas Comerciais Comestíveis. Polímeros, v. 22, n. 5, p. 486-490, 2012.

- LindebOOM, N., CHANG, P.R., TYLER, R.T. Analytical, biochemical and physicochemical aspects of starch granule size, with emphasis on small granule starches: a review. Starch - Starke, v. 56, p. 89-99, 2004.

- LOPES, ARAÚJO, W., FASCIO, MIGUEL. Esquema para Interpretação de Espectros de Substâncias Orgânicas na Região do Infravermelho. Instituto de Química, Universidade Federal da Bahia, Campus Universitário de Ondina, Salvador - BA. 2004.

LY, O.; BASKO, D.M. Theory of electron spin resonance in bulk topological insulators Bi2Se3, BisTe3 and Sb2Te3. Journal of Physics: Condensed Matter, v. 28, n. 15, p.155801- 8, 2016.

- MAEDA, K.C.; CEREDA, M. P. Avaliação de duas metodologias de expansão ao forno do polvilho azedo. Ciência e Tecnologia dos Alimentos, v.61, p,139-143, 2001.

- MANN, J., J. H. CUMMINGS., H. N. ENGLYST., T. KEY., S. LIU., G. RICCARDI., C. SUMMERBELL., R. UAUY., R. M. VAN DAM., B. VENN., H. H. VORSTER., AND, M. WISEMAN. FAOMHO Scientific Update on carbohydrates in human nutrition: Conclusions. European Journal of Clinical Nutrition, v. 61 (Suppl 1), S132-S137, 2007.

- MANTSCH, H. H.; CHAPMAN, D. Infrared Spectroscopy of Bio molecules. New York: John Wiley \& Sons, 1995. 
- MASTRO, N.L.d. Noções de Química da Radiação em sistemas biológicos. Publicação IPEN 276. São Paulo, 1989. (ISSN 0101-3084).

- McMillaN, J.A. Paramagnetismo eletrônico. Washington, 1973. 115p. Monografia - Departamento de Assuntos Científico de La Secretaria General de La Organizacion de Los Estados Americanos.

- MURANO, E. A. Microbiology of irradiated food. In: Food Irradiation: A Source Book. Edited by E. A. Murano. lowa State University Press, Ames, lowa, USA, 1995.

- NAKAGAWA, K.; KOBUKAI, K.; SATO, Y. ESR investigation of sucrose radicals produced by $0.25-4.5$ Gy doses of X-ray irradiation. Journal of Radiation Research, v. 55, p. 726-729, 2014.

- OliveIRA, M.R.R. Avaliação por RPE do potencial antioxidante de variedades de soja irradiadas com 60Co. Tese, IPEN-USP, 2009.

- POLESI, F.L. Propriedades físico-químicas, nutricionais e sensoriais de grãos e amido de arroz submetidos á radiação gama. Tese, CENA/USP, 2014.

- RAFFI, J.; MICHEL, JP.; SAINT-LEBE, L. Theoretical study of the depolymerization osf starch under the combined action of protons and gamma radiation. Starch/Starke, v. 32, p. 262-5, 1980.

- RAFFI, J.; STOCKER, P. electron paramagnetic resonance detection of Irradiated Foodstuffs. Appl. Magn. Reson. v. 10, p. 357-373, 1996.

- RAMAZAN, K.; IRUDAYARAJ, J.; SEETHAEAMAN, K. Characterization of Irradiated Starches by Using FT-Raman and FTIR Spectroscopy. J. Agric. Food Chem., v. 50, n. 14, p. 3912-3918, 2002.

- RHODES, C. J. Electron Spin Resonance. Annual Reports Section "C" (Physical Chemistry), v.107, p. 47-87, 2011.

- ROBERTSON, J.A.; SUTCLIFFE, L.H. ESR investigation of starch gelatinization using novel spin probes. Magn. Reson. Chem., 43, pp.457-462, 2005.

- ROQUE, F. NIDIA. Substâncias Orgânicas : Estrutura e Propriedades. Ed Edusp. São Paulo, 2011. 
- SALA, O. Fundamentos da Espectroscopia Raman e no Infravermelho. Ed UNESP, 2008.

- SCHRAMM, D.U.; CATTANI, M.M., MASTRO, N.L.D.; ROSSI, A.M. Electron spin resonance (ESR) of gamma-irradiated oyster shells. Anais do VI Congresso Geral de Energia Nuclear, Rio de Janeiro, outubro 1996, 1, p. 1-4, 1996.

- SILVERSTEIN, R. M; BASSLER, G. C., MORRILL, T C.; Spectrometric Identification of organic compounds, v.5, 1991.

- SLICHTER, C.P. Principles of Magnetic Resonance. 3 ed. Berlim, SpringerVerlag, 1990. Cap. 1, p.1-4: Elements of Resonance.

- SOLOMONS, T.W.G. Química Orgânica. Vol. I. Ed: LTc, Curitiba, 2005.

- TAKINAMI, P.Y.I. Obtenção de biopolímeros de gelatina por radiação ionizante. Tese, IPEN-USP, 2014.

- TEIXEIRA, C.A.H.M. Efeito da radiação ionizante em diferentes tipos de farinhas utilizadas em tecnologia de panificação. Dissertação de mestrado. IPEN-USP, 2011.

- TESteR, F., KARKALAS, J.; QI, X. Starch Composition, fine structure and architecture. J. Cereal Sci., v. 39, p. 151-165, 2004.

- $\quad$ THOMAS, D.J.; ATWELL, W. Starches: Pratical Guides for the Food Industry. Minessota:Eagan Press, 1999. 94p.

- TOPPING, D.L., CLIFTON, P.M. Short-chain fatty acids human colonic function: role of resistant starch and non-starch polysaccharides. Physiol. Rev., v. 81, p.1031-64, 2001.

- $\quad$ TyPleR, P.A.; LLEWELlyN, R.A. Física Moderna. 6a Edição. Ed. LTC, São Paulo, 500p, 2014.

- UEHARA, V.B. Efeito da radiação gama em propriedades da farinha de banana verde. Dissertação de mestrado. IPEN-USP, 2011.

- WERTZ, J.E.; BOLTON, J.R. Electron Spin Resonance - Elementary Theory and Practical Applications. 1. Ed. New York, McGraw - Hill Company, 1972. Cap. 2, p.21-36; Basic Instrumentation of Eletctron Spin Resonance. 
